\title{
Parametrical study of masonry walls subjected to in-plane loading through numerical modeling
}

\author{
Vladimir G. Haach ${ }^{1}$ \\ Graça Vasconcelos ${ }^{2}$ \\ Paulo B. Lourenço ${ }^{3}$ \\ 1 - Professor, University of Sao Paulo, Department of Structures, Av. Trabalhador Saocarlense, \\ 400, 13566-590, Sao Paulo - SP, BRAZIL, Phone: (+55) 1633739455 , \\ Fax: (+55) 16 33739482, E-mail: vghaach@sc.usp.br (Corresponding author) \\ 2 - Professor, ISISE, Department of Civil Engineering, University of Minho, Azurém, 4800- \\ 058 Guimarães, PORTUGAL, E-mail: graca@civil.uminho.pt \\ 3 - Professor, ISISE, Department of Civil Engineering, University of Minho, Azurém, 4800-058 \\ Guimarães, PORTUGAL, E-mail:pbl@civil.uminho.pt
}

Abstract. This paper deals with the numerical assessment of the influence of parameters such as pre-compression level, aspect ratio, vertical and horizontal reinforcement ratios and boundary conditions on the lateral strength of masonry walls under in-plane loading. The numerical study is performed through the software DIANA ${ }^{\circledR}$ based on the Finite Element Method. The validation of the numerical model is carried out from a database of available experimental results on masonry walls tested under cyclic lateral loading. Numerical results revealed that boundary conditions play a central role on the lateral behavior of masonry walls under in-plane loading and determine the influence of level of pre-compression as well as the reinforcement ratio on the wall strength. The lateral capacity of walls decreases with the increase of aspect ratio and with the decrease of pre-compression. Vertical steel bars appear to have almost no influence in the shear strength of masonry walls and horizontal reinforcement only increases the lateral strength of masonry walls if the shear response of the walls is determinant for failure, which is directly related to the boundary conditions.

Key words: shear, in-plane behavior, numerical analysis, parametrical analysis, masonry walls. 


\section{Introduction}

Masonry is an excellent structural system when compressive stresses control the ultimate response. Though, it is well known that the low tensile strength of masonry might lead to an inadequate response when lateral forces reach high values. Reinforcement appears to be a solution to increase the tensile strength and thus to improve the mechanical behaviour of masonry under lateral loading.

Masonry shear walls exhibit a complex structural behavior since masonry is a composite material with anisotropic behavior and shear walls are subjected to a bi-axial stress state. Several experimental studies on masonry shear walls have been carried out in order to evaluate and better understand their behavior under seismic loads (Priestley and Bridgeman [1], Tomaževič and Zarnic [2], Shing et al. [3], Mahmoud et al. [4], Zhuge et al. [5], Magenes and Calvi [6], Magenes [7], Schultz et al. [8], Tomaževič [9], Bosiljkov et al. [10], Yoshimura et al. [11], Vasconcelos [12], Voon and Ingham [13], Steelman and Abrams [14], Mosele et al. [15], ESECMaSE project [16], DISWall project [17]). However, a number of drawbacks occurs in experimental analysis since the test setups are usually complex (the real boundary conditions are hard to be known and represented), experimental setups are generally expensive, and results are sometimes scarce and limited to the conditions in which they have been obtained. Complementarily to experimental analysis, numerical modeling of masonry walls under horizontal loads contributes to increasing knowledge about their behavior, once it is validated variations of parameters that can influence the in-plane behavior can be analyzed. 
There are basically two numerical approaches that have been adopted by researchers to describe the mechanical behavior of masonry: macro-modeling and micro-modeling (Lourenço et al. [18], Lourenço and Rots [19]). In macro-modeling, masonry is considered as a composite and homogeneous material while in case of micro-modeling masonry is considered as a discontinuous assembly of units connected by joints simulated by appropriate constitutive laws.

For the macro-modeling approach, Lourenço et al. [18] presented a failure criterion for masonry based on an extension of conventional formulations for isotropic quasibrittle materials to describe the orthotropic behaviour. Another macro-model was developed by El-Dakhakhni et al. [20] to predict the in-plane behavior of concrete masonry. It is a multilaminate model where the masonry assemblage is replaced by an equivalent material which consists of a homogenous medium intersected by two sets of planes of weakness along the head and bed joints. Related to macro-modelling there are still other models in the literature (Gambarotta and Lagomarsino [21], Asteris and Tzamtzis [22]).

For the micro-modeling approach, Lourenço and Rots [19] proposed an interface cap model based on modern plasticity concepts, capable of capturing all masonry failure mechanisms, namely tensile cracking, frictional slip and crushing along interfaces. Similar cap models were proposed by Sutcliffe et al. [23] and Chaimoon and Attard [24], with the consideration of a linear compression cap model, which seems to be an interesting simplification that can be applied in complex analysis of masonry structures.

Numerical modeling of masonry structures can effectively be useful for a better understanding of the mechanical behavior of masonry walls for scenarios different from the ones tested at laboratory. Thus, the main goal of the present work is the evaluation 
of the influence of the main parameters such as the boundary conditions, vertical precompression, presence of vertical and horizontal reinforcement, filling of vertical joints and horizontal and vertical reinforcement ratios, on the lateral behavior of reinforced concrete block masonry walls through a numerical analysis.

\section{Brief description of experimental tests}

As mentioned above, the numerical model has been validated from the experimental results of in-plane tests carried out on concrete block masonry walls. The detailed description of the experimental results is available in Haach et al. [25] and Haach [26]. The experimental program consisted of in-plane cyclic tests on cantilever concrete block masonry walls following the typical test setup shown in Fig. 1 used for masonry walls under combined vertical and horizontal load (Vasconcelos and Lourenço [27]). The testing procedure was divided in two phases. First, the vertical load was applied at a rate of $0.25 \mathrm{kN} / \mathrm{s}$ up to a vertical stress equal to $1.30 \mathrm{MPa}$ or $0.56 \mathrm{MPa}$ depending on the selected level of pre-compression, which was kept constant during the test. After that, horizontal displacements were imposed to the walls until de failure. The cyclic tests were carried out under displacement control at a rate of $70 \mu \mathrm{m} / \mathrm{s}$ by means of an external LVDT connected to the horizontal actuator. The dimensions and reinforcement details for the walls are summarized in Table 1 . Here, $\rho_{v}$ and $\rho_{h}$ are the vertical and horizontal reinforcement ratios respectively. The specimens are denoted by $N x-y$, where $x$ indicates the vertical pre-compression force in $\mathrm{kN}$ and $y$ is an optional distinct characteristic. This optional characteristic is UM, for unreinforced masonry, SH for the specimen wall reinforced only at bed joints, PA for lowest horizontal reinforcement ratio, and MA for highest horizontal reinforcement ratio. Hollow concrete 
units of 201mm(length) x 93mm(thickness) x 100mm(height) were considered in the experimental program. These units have two cells with $60 \mathrm{~mm} \times 70 \mathrm{~mm}$ and one small cell in the middle of unit with $15 \mathrm{~mm} \times 70 \mathrm{~mm}$, where vertical reinforcement is located. The percentage of holes in the block is about 46\%, which, according to Eurocode 6 [28], indicates that the units belong to Group 2. Prefabricated trussed reinforcement composed of two longitudinal bars connected by diagonal bars was used for vertical and horizontal reinforcement.

The pre-compression level and the vertical and horizontal reinforcement ratios were the variables analyzed in the experimental study. The percentage of vertical reinforcement $\left(\rho_{v}=0.098 \%\right)$ was kept constant for all walls with the exception of specimen N60- UM (unreinforced masonry wall) and specimen N60-SH, in which only horizontal reinforcement was used. Two levels of vertical pre-compression are considered, corresponding to a normal stress level of 0.56MPa and 1.30MPa. Apart from specimen N60-MA, which presented 4 horizontal steel bars and specimen N60SH, which presented only 3 horizontal steel bars without vertical reinforcements, reinforced specimens presented 3 vertical reinforcements and 3 horizontal reinforcements. Reinforced concrete beams were placed at bottom (280 mm x $280 \mathrm{~mm}$ x $1400 \mathrm{~mm}$ ) and at top (280 $\mathrm{mm} \times 280 \mathrm{~mm} \times 1200 \mathrm{~mm}$ ) of the walls in order to anchor the vertical reinforcements and to ensure an uniform distribution of the applied vertical and horizontal loads. The displacements of the walls and strains of reinforcements under cyclic loading were measured by means of a set of LVDTs and strain-gauges.

A more detailed overview of the experimental results can be found in Haach et al. [25] and Haach [26]. 


\section{Numerical modeling}

The numerical model applied to study reinforced concrete block masonry under inplane loading was defined using the software DIANA ${ }^{\circledR}$. The micro-modeling approach was chosen for the simulation since it includes all the basic failure mechanisms that characterize masonry, enabling the detailed representation of resisting mechanisms of the walls. In the numerical analysis only monotonic loading was considered, as the focus here is on the parametric analysis. Newton-Raphson iteration procedure was used with a displacement control and an energetic convergence criterion with a tolerance of $10^{-3}$

The validation of the numerical model was carried out based on the experimental results of the in-plane walls, being the parametric analysis performed in a wall with $1400 \mathrm{~mm}$ height (14 courses), 1400mm length and 100mm width. In case of variation of the height to length ratio five aspect ratios $(h / L)$ of $2.33,1.40,1.00,0.78$ and 0.64$)$ were considered. Walls had constant height and different lengths in parametric analysis. As in case of experimental tests, a concrete beam was also modeled at the top of walls and the lateral loading was applied at the mid height of the concrete beam.

\section{Finite element mesh}

The mesh was composed of continuum and interface elements to represent respectively the masonry units and the masonry joints. In case of the units, eight-node isoparametric plane-stress distribution elements with Gauss integration scheme were adopted. Each masonry unit was modeled with two continuum elements. Potential 
vertical cracks of the units were introduced at mid length of the units. The joints were lumped into the concrete units and the unit-mortar interface was represented by six node interface elements with quadratic interpolation, see Fig 2.

The upper concrete beam was modeled in order to replicate the experimental tests, see Fig. 3. The bottom concrete beam was not included because its use in experimental tests was restricted to the anchorage of vertical reinforcements. Reinforcement was modeled through embedded bars. Reinforcement strains were computed from the displacement field of the continuum elements (structural elements), meaning that a perfect bond between the reinforcement and the surrounding masonry was adopted.

\section{Boundary conditions}

When considered as an integrant part of a structural masonry building, masonry walls tend to behave with top and bottom boundaries mostly fixed, meaning that restriction is effective in both ends. The boundary conditions assume a central role on the lateral behavior of masonry walls as it governs the preponderant failure mechanism of the walls under horizontal cyclic loading. Due to the difficulty of simulating fixed ends of the walls at the laboratory, it is common to consider cantilever walls on the experimental research programs. In this case, the top end of the walls is able to rotate. For this reason, in the parametric analysis two different boundary conditions were considered to evaluate their influence on the in-plane behavior of the concrete block masonry walls. 
In cantilever walls, the continuum elements representing the masonry units located at the base of wall were connected to interface elements which were fully fixed in order to represent the fixed base of the masonry walls. The upper beam was connected to the wall through interface elements modeled with linear behaviour and infinite stiffness to simulate a perfect bond between these two elements, as observed in the experimental tests. In case of fixed ends walls the top concrete beam had all degrees of freedom were fully restrained.

\section{Material models and mechanical properties}

In the micro modeling approach all constituent materials of the reinforced concrete block masonry walls, with distinct mechanical properties, are independently described. Distinct material models were used to represent the behavior of the concrete of the top beam, steel reinforcement, concrete masonry units, vertical and horizontal joints and the potential cracks in the middle of units. The mechanical properties used in the description of the material models were obtained from experimental tests carried out on materials and masonry assemblages (Haach [26]).

Isotropic elasticity was adopted for the upper concrete beam since the stresses developed in this element are very small and thus linear stress-strains relationship is valid. An elastic modulus equal to $30 \mathrm{GPa}$ was used for the concrete of beams, corresponding to a concrete with a compressive strength of about $30 \mathrm{MPa}$.

The non-linear behavior of the concrete masonry units was represented by a Total Strain Crack Model based on a fixed stress-strain law concept available in the commercial software DIANA ${ }^{\circledR}$. It describes the tensile and compressive behavior of the 
material with one stress-strain relationship in a coordinate system that is fixed upon crack initiation. Exponential and parabolic constitutive laws were used to describe the tensile and compressive behavior of concrete masonry units respectively, see Fig. 4 . The mechanical properties needed to describe this material model are the elastic modulus of concrete units $(E=9.57 \mathrm{GPa})$, the Poisson's ratio of concrete units $(v=0.20)$, the tensile and compressive strength of concrete units $\left(f_{t u}=3.19 \mathrm{MPa}\right.$ and $f_{c u}=12.13 \mathrm{MPa}$, respectively), the fracture energy of units under tension and compression $\left(G_{f u}{ }^{I}=0.06\right.$ $\mathrm{N} / \mathrm{mm}$ and $G_{c u}=10.00 \mathrm{~N} / \mathrm{mm}$, respectively) and the shear retention factor $(\beta=0.01)$. Due to the impossibility of obtaining the post-peak behavior in tension and compression of the three cell concrete units, the values of fracture energy, both in tension and compression, were obtained from the experimental results obtained by Mohamad [29] in concrete blocks with similar raw materials composition. The shear behavior during cracking was described through a shear retention model defined by a constant value, see Fig. 4c.

An interface cap model with modern plasticity concepts proposed by Lourenço and Rots [19], and further enhanced by Van Zijl [30], was used for interface elements describing the masonry joints. The interface material model is appropriate to simulate fracture, frictional slip as well as crushing along material interfaces, which are the possible failure modes of the masonry unit-mortar interfaces. Among the mechanical properties used for the definition of the yield functions in tension, compression and shear of the unit-mortar interfaces are the normal and transversal stiffness of bed joints $\left(k_{n}=20 \mathrm{~N} / \mathrm{mm}^{3}\right.$ and $k_{s}=48 \mathrm{~N} / \mathrm{mm}^{3}$, respectively). The normal stiffness was calculated based on the results of the direct tensile tests carried out to characterize the tensile bond strength of the unit-mortar interface (Vasconcelos et al. [31]). The shear stiffness was 
obtained through the results of the shear tests carried out on triplet specimens to characterize the shear behavior of concrete unit-mortar interface (Haach [26]).The yield function with exponential softening for the tension cut-off model requires the knowledge of the tensile bond strength of bed joints $\left(f_{t}=0.33 \mathrm{MPa}\right)$ and the mode I fracture energy $\left(G_{f}^{I}=0.017 \mathrm{~N} / \mathrm{mm}\right)$. The bond tensile strength was obtained from the experimental results of flexural tests of masonry carried out in the direction parallel to bed joints (Haach [26]). Due to the difficulty of obtaining mode I fracture energy of the unit-mortar interface, this mechanical property was defined by fitting the numerical to experimental results obtained in the masonry walls.

The behaviour of the masonry material in compression is modelled by a constitutive law, composed of a parabolic hardening rule and a parabolic exponential softening branch (Lourenço and Rots [19]). For the definition of this constitutive it is needed the knowledge of the compressive strength $\left(f_{a}=5.95 \mathrm{MPa}\right)$, compressive fracture energy $\left(G_{c}=5.00 \mathrm{~N} / \mathrm{mm}\right)$, which were obtained from uniaxial compressive tests carried out on masonry wallets, and additionally of the parameter $C_{s s}$ to take into account the contribution of shear stress to failure $\left(C_{s s}=5.3\right)$, defined by fitting the numerical to experimental results obtained in the masonry walls.

The shear behavior of the unit-mortar interfaces is represented by the Coulomb failure criterion. The definition of this function is made through the knowledge of the cohesion ( $c=0.42 \mathrm{MPa})$, friction coefficient $(\mu=0.49)$, the dilatancy coefficient (tan $\psi$ $=0.52)$, and the shear fracture energy $\left(G_{f}^{I I}=2.0 \mathrm{~N} / \mathrm{mm}\right)$. In order to capture cohesion softening and friction softening the residual friction coefficient $\left(\mu_{\text {res }}=0.43\right)$ should be obtained. All the parameters were obtained from the tests carried out on triplet specimens (Haach [26]). In the model, the dilatancy is considered to be dependent on 
the normal confining stress and on the shear slipping. Thus, for the correct definition of the dilatancy, the confining normal stress at which the dilatancy becomes zero ( $\sigma_{u}=$ $1.35 \mathrm{MPa})$ and the dilatancy shear slip degradation coefficient $(\delta=1.64)$, were also obtained by experimental analysis.

In case of the dry vertical joints, the shear behavior was also modeled based on the Coulomb criterion, with null cohesion and a friction coefficient corresponding to the dry contact between two surfaces of concrete $(\mu=0,65)$. Very low values of normal and transversal stiffness $\left(2 \mathrm{~N} / \mathrm{mm}^{3}\right)$ were considered, being null the tensile strength.

According to Lourenço and Rots [19], it is useful to model potential cracks in units in order to avoid an overestimation of the collapse load and of the stiffness. .Thus, potential cracks placed at the middle length of units were considered through interface elements with a discrete cracking model. High stiffness should be considered for this interfaces according to Lourenço and Rots [19] $\left(k_{n}=10^{6} \mathrm{~N} / \mathrm{mm}^{3}\right.$ and $k_{s}=10^{6} \mathrm{~N} / \mathrm{mm}^{3}$, respectively). In addition, an exponential softening behavior was adopted for the tensile behavior of these interfaces with the tensile bond strength $\left(f_{t}=3.19 \mathrm{MPa}\right)$ and the mode I fracture energy $\left(G_{f}^{I}=0.06 \mathrm{~N} / \mathrm{mm}\right)$ obtained in uniaxial compressive tests carried out on the concrete units (Haach [26]). The constitutive law for discrete cracking in DIANA $^{\circledR}$ is based on a total deformation theory, which expresses the stresses as a function of the total relative displacements.

Elasto-plastic behavior was adopted for the reinforcements through the yield criterion of Von Mises. As the reinforcement elements overlap the interface elements representing the masonry joints, and thus have traction components in the same directions as the interface elements (normal and shear components), a 'free length' (thickness of the joints) is needed in order to account properly for the stiffness of the 
interface crossed by the reinforcement, see Fig. 5. Reinforcements increase considerably the stiffness of interface elements leading to an ill-conditioned stiffness matrix. According to DIANA ${ }^{\circledR}$, the equivalent normal and shear stiffness of the interface elements crossed by the steel reinforcements is given by Eq. 1 and Eq. 2 .

$$
\begin{aligned}
& k_{n}=\frac{E_{s}}{l_{f r}} \\
& k_{s}=k_{t}=\frac{E_{s}}{2 l_{f r}}
\end{aligned}
$$

where, $E_{s}$ is the elastic modulus of reinforcements and $l_{f r}$ is the thickness of mortar joints.

It should be stressed that the presence of reinforcements increases the number of iterations needed to achieve convergence and consequently the computational effort.

\section{Validation of numerical model}

The assessment of the influence of the selected parameters on the in-plane behavior of masonry wall was preceded by the calibration of the numerical model of Lourenço and Rots [19] existing in DIANA ${ }^{\circledR}$ based on the experimental results obtained in the tests carried out on concrete block masonry walls under in-plane cyclic tests. As mentioned before, the mechanical properties such as fracture energies of unit-mortar interfaces and normal and transversal stiffness of vertical dry joints were calibrated in order to fit the numerical to experimental results obtained in the masonry walls. It should be noticed that in the end of calibration the same properties have been adopted for all masonry walls analyzed. 
The calibration of the numerical model was carried out based on the comparison between the numerical and experimental failure modes, monotonic envelops of the force-displacement diagrams and on the strains developed in the steel reinforcements. In Fig. 6 a comparison between experimental monotonic envelop is illustrated. It is observed that the force-displacement numerical envelop fits the experimental monotonic envelop very well, both in terms of maximum lateral resistance and initial stiffness. The maximum difference between experimental and numerical lateral strength is of about $10 \%$.

As shown in Fig. 7 the numerical results replicate the three main crack patterns developed in unreinforced masonry walls,, namely initial flexural cracking, diagonal cracking and crushing at the bottom of the wall. In the experimental test, after the diagonal crack and crushing at the bottom corner occurred, the upper part of the walls slide over the diagonal crack. In case of the specimen reinforced only at the bed joints (N60-SH) the horizontal reinforcement controlled the diagonal cracking and only the flexural crack developed similarly to the experimental results. In case of specimens where vertical and horizontal reinforcements were combined, diagonal cracks were more distributed and flexural crack was controlled by the vertical reinforcement following the experimental results.

Numerical strains at the reinforcements approach reasonably well the experimental results. Horizontal reinforcements exhibited almost no strains until diagonal cracking. After diagonal cracking, the effectiveness of the horizontal reinforcement is revealed by a clear discontinuity on the strain diagram as shown in Fig. 8a. In numerical modeling, the vertical reinforcement behaves in a similar manner to the experimental results, see Fig. 8b. It is noted that the lower strains obtained in the 
numerical analysis can be partly attributed to the permanent plastic deformations accumulated during cyclic loading.

Based on the comparison between numerical and experimental main results, it can be concluded that the numerical model is able to reproduce the experimental mechanical behavior of reinforced and unreinforced masonry walls under combined vertical and shear loads, meaning that it is suitable to be used on the parametric analysis.

\section{Parametric analysis}

After the validation of the numerical model, a parametric analysis was performed for the assessment of the influence of different parameters on the lateral behavior of the concrete masonry walls. The parameters under study are:

(a) geometry of the walls. The height to length ratio $(h / L)$, assuming values of 2.33 , $1.40,1.00,0.78$ and 0.64 .

(b) pre-compression level $\sigma / f_{a}=0.0,0.1,0.2,0.4$ and 0.6 ; The pre-compression is considered to be a percentage of the compressive strength of masonry.

(c) boundary conditions. Since the connections between masonry walls and concrete slabs are variable and the fixing degree is sometimes uncertain, two limit boundary conditions were adopted. Thus, the walls were considered either as cantilever and fixed at both ends.

(d) variation of the horizontal reinforcement ratio at the bed joints $\left(\rho_{h}\right)$ from $0.00 \%$ to $0.03 \%, 0.05 \%$ and $0.08 \%$; 
(e) variation of the vertical reinforcement ratio at the internal vertical cores of $\left(\rho_{v}\right)$, from $0.00 \%$ to $0.03 \%, 0.05 \%$ and $0.08 \%$;

(f) interaction of horizontal and vertical reinforcement with distinct combinations of vertical and horizontal reinforcements

It should be stressed that the parametric analysis encompasses also the evaluation of the interaction along the parameters under analysis. Thus, the evaluation of the influence of the geometry of the wall, vertical and horizontal reinforcement is made for variable boundary conditions and for variable pre-compression levels. It is well known that the variation on the vertical pre-compression and even the boundary conditions results in distinct crack patterns and failure modes. Therefore, the consideration of the two distinct boundary conditions, variation of the pre-compression level and the distinct height to length rations aims also at assessing the influence of the failure modes on the performance of the vertical and horizontal reinforcements and their corresponding variation ratio. It should be stressed that the numerical simulation was effectively a need to develop an analytical model, which is provided in Haach [19], as the experimental results were not completely conclusive due to the limited number of tested specimens. Among this, the doubts on the contribution of horizontal and vertical reinforcements to the lateral strength are here clarified.

\section{Analysis 1- Influence of the geometry of the walls}

The variation of the lateral resistance of unreinforced masonry walls for variable aspect ratios, by considering both cantilever and fixed end walls, and adopting varied pre-compression levels is indicated in Fig. 9. The variation of these parameters results 
in the analysis of a total of 25 walls. It is observed that the relation between lateral resistance of unreinforced masonry walls and the aspect ratio is well described by a power function independently on the boundary conditions and on the level of precompression. As observed by other authors the lateral resistance of masonry walls increases as the height to length ratio decreases (Anthoine et al. [32], Schultz et al.[33] and Kikuchi et al. [34]). It is also seen that the increasing on the pre-compression level improves the lateral strength of the walls for the different values of height to length ratio, similarly to what has been pointed out in literature (Drysdale et al. [35], Vasconcelos and Lourenço [27]).

The relation between the lateral resistance and the pre-compression level is well described by a parabolic function, see Fig. 10, for the distinct aspect ratios and for both boundary conditions. This result is also in accordance to results pointed out by Drysdale et al. [35].

From the numerical analysis it is seen that the lateral strength increases up to a pre-compression level of about $40 \%$ of the compressive strength of masonry, after which a progressive decrease on the lateral resistance occurs. This level of precompression determines an important change on the failure mode of the walls. After this stage the compressive failure takes a key role in the lateral in-plane behaviour of the masonry walls, being this result valid for both boundary conditions of the walls. Additionally, it is also observed that the compressive failure is more important as the aspect ratio decreases, which is revealed by the higher curvature of the parabolic function.

The three dimensional failure surfaces of the unreinforced walls under in-plane loading were obtained by combining simultaneously the aspect ratio $(h / L)$ and 
normalized axial stress $\left(\sigma / f_{a}\right)$ with the lateral resistance, $(H)$, see Fig. 11 . The failure surface presents the same shape for both boundary conditions. The difference between cantilever and fixed end conditions is the level of the lateral resistance of he walls, which is higher in case of walls with both ends fixed due to the lower lever arm. In both cases, the surface curvature presents decreasing values as the aspect ratio increases and as the compressive stress level decreases, which is directly related to the predominant failure mode of the walls. Under high values of pre-compression and low aspect ratios, the shear failure prevails and the lateral resistance is more sensitive to low variations of these parameters. This means that the variation of the pre-compression level and aspect ratio play a major role on the lateral strength of walls, if the lateral in-plane behavior is controlled by a shear mechanism. The influence on the variation of these parameters is not so evident in walls governed mostly by flexural mechanism.

An analysis of the failure modes developed in shear walls with distinct boundary conditions and with variable aspect ratio and pre-compression level was also performed. The results of numerical modeling concerning the failure modes of the walls are displayed in Table 2. From the analysis of the numerical results, it was observed that it is possible to standardize the typical failure modes according to the following description:

1. Flexure (FL)

a. Rocking (R) - when an horizontal crack opened in base of wall due to the tensile stresses and the wall rotated around the bottom corner;

b. Crushing (C) - when early horizontal flexural cracking reduce the effective cross section of the walls and toe crushing of wall occurs due to the concentration of high compressive stresses at the toes of the wall. 
2. Shear (SH) - mainly associated to diagonal cracking (a stepped crack along the unit mortar interfaces or a straight crack through unit-mortar interfaces and masonry units;

It is possible to confirm that flexure failure modes were predominant in cantilever walls, for low levels of pre-compression and for high aspect ratios. In case of cantilever slender walls $(h / L=2.33$ and $h / L=1.4)$, flexural rocking mechanism predominates for all pre-compression levels under analysis. For squared walls toe crushing develops for high pre-compression levels. Shear failure develops only for aspect ratios lower than 1.0 and for medium to high pre-compression levels. When no pre-compression was applied, flexural rocking failure mechanism characterized the behaviour of the walls with distinct boundary conditions. In case of fixed end walls, apart from the walls submitted to zero pre-compression level and the highest slender wall, in which flexural rocking mechanism prevails, the shear failure mode predominates in the lateral response of unreinforced masonry walls. All failure modes are found for certain values of aspect ratios and pre-compression levels defining failure regions. The definition of the failure modes of some walls located along the boundaries is difficult because the diagonal cracking or toe crushing develops almost at same time. The understanding of the predominant failure mode of masonry shear walls is rather important for the analysis of the influence of parameters such as vertical and horizontal reinforcement ratio on the in-plane behavior, because their performance depends to great extent on the failure mode exhibited by the walls.

Its should be stressed that the standardization of the failure modes is important for the derivation of the analytical model developed for concrete masonry walls (Haach [26]). 


\section{Analysis 2 - Evaluation of the individual contribution of the horizontal reinforcement}

In the assessment of the influence of the horizontal reinforcement on the lateral resistance of the concrete block masonry walls, a total of 9 walls was considered for each type of boundary conditions, namely 5 walls with variable aspect ratios with a precompression $\sigma / f_{a}$ equal to 0.2 and 4 walls with an aspect ratio $(h / L)$ of 1.0 and the variable pre-compression levels adopted in the previous analysis. Three horizontal reinforcement ratios were taken into account: $0.03 \%, 0.05 \%$ and $0.08 \%$. Horizontal reinforcement was uniformly distributed along the height of the walls in five layers. Bars were symmetrically positioned with respect to the mid height at each three courses.

Results clearly show that the boundary conditions have a major influence on performance and contribution of the horizontal reinforcements to the lateral strength of the reinforced masonry walls. In case of cantilever walls, only for low aspect ratios ( $h / L=0.64$ ) a slight increase on the lateral strength was observed, when comparing reinforced to unreinforced masonry walls, see Fig. 12. In fact, horizontal reinforcements contribute to the lateral strength of the walls only after the onset of the diagonal crack. In case of cantilever walls diagonal cracking develops before the achievement of the maximum lateral resistance only in case of very low aspect ratios, which means that the reinforcement is not activated when flexural response is preponderant. A similar trend was observed in fixed end walls for levels of vertical pre-compression up to $\sigma / f_{a}=0.1$, after which it is clear that the increase on the horizontal reinforcement ratio leads to increasing values of the lateral strength, see Fig. 13. Above this pre-compression level the shear prevails in the response of the walls, being the horizontal reinforcements 
activated after opening of the diagonal cracking. In this case the horizontal reinforcements avoid the separation of the walls into two parts and promote the stress transfer between both edges of the diagonal crack. It should be noticed that the trend of overturning of one part of the wall in case of unreinforced masonry walls is prevented by the presence of horizontal reinforcements. It is important to stress that a perfect bond between the reinforcements and the mortar of bed joints was considered in the numerical analysis. In design of masonry walls it is mandatory to ensure the required bond length for bed joint reinforcements so that they can be effective for the contribution to the lateral resistance of the walls. The comparison of the results found for cantilever and fixed-fixed ends masonry walls show that the boundary conditions play a central role on the performance of the horizontal reinforcement to the lateral behavior of masonry walls as in cantilever walls, the flexural behavior is much more remarkable.

Independently on the boundary conditions, it becomes clear that the horizontal reinforcement ensures a control of the diagonal cracking, increases the deformation capacity, providing a higher ductility for the masonry wall and enabled a better distribution of the stresses in the wall, see Fig. 14.

As aforementioned the reinforced masonry walls subjected to in-plane loading can also fail by mixed flexure-shear mode (M), as can be confirmed through Table 3, where the identification of the failure mode of the reinforced masonry walls according to two boundary conditions, variable height to length ratio and variable compressive stress is indicated. This mixed failure develops when both flexural and shear resisting mechanism contribute to the final resistance of the masonry wall. The typical shearflexure failure mode is characterized in a first phase by diagonal cracking due to the 
tensile stresses perpendicular to the diagonal flow of compressive stresses. Due to the presence of horizontal reinforcement, the failure by diagonal cracking is prevented and the increase on the lateral load leads to the crushing of masonry due to high compressive stresses. This means that the shear failure mode can change to mixed flexure-shear failure mode due to the increase on the horizontal reinforcement ratio, see Table 3, being this trend valid for both boundary conditions.

Analysis 3 - Evaluation of the individual contribution of the vertical reinforcement

In order to obtain a better insight on the influence of the vertical reinforcement on the behavior of concrete block masonry walls under lateral loads, it was decided to consider distinct vertical reinforcement ratios. Also in this analysis, a total of 9 walls were considered for each type of boundary conditions, namely 5 walls with variable aspect ratios $(h / L)$ and a pre-compression $\left(\sigma / f_{a}\right)$ equal to 0.2 and 4 walls with an aspect ratio $(h / L)$ of 1.0 and variable pre-compression levels $\left(\sigma / f_{a}\right)$ from 0 to 0.6 . Three vertical reinforcement ratios were adopted in the analysis, namely $0.03 \%, 0.05 \%$ and $0.08 \%$. Four vertical reinforcements were uniformly distributed along the height of the walls, except in specimen with $h / L=2.33$, where only three vertical reinforcements were considered due to its small length.

From Fig. 15 and Fig. 16, it is observed that the contribution of vertical reinforcements depends on the failure mode developed in the walls. It is clear that the vertical reinforcements increased the lateral strength of cantilever and fixed end walls when the flexural resisting mechanism governs the lateral response of the walls. This 
behavior is clearly seen in cantilever walls. It is common that in unreinforced cantilever masonry walls and especially for high aspect ratios, the horizontal load generates tensile stresses at the base of wall leading to the development of horizontal cracks in the first courses and to the uplift until crushing of the opposite bottom corner (flexural rocking mechanisms). Observing the failure modes in Table 4 it can be noticed that unreinforced masonry walls which failed by rocking, failed by the yield of vertical reinforcement (FL (Y)) when the vertical reinforcements are added in a reduced ratio. The vertical reinforcements reduce the uplift and resist to tensile stresses leading to the increase on the lateral strength. It should be stressed as the contribution of vertical reinforcement to the lateral strength depends on the failure modes, it also depends on the boundary conditions and on the level of pre-compression of the wall, particularly in case of fixed end masonry walls. Thus, the benefit of the vertical reinforcement ratio on the lateral strength is not straightforward due to the predominance of the diagonal cracking for medium to high levels of vertical pre-compression. When unreinforced masonry walls fail by shear diagonal cracking, the introduction of vertical reinforcements can lead to a reduction on the lateral strength of the wall. The horizontal load applied in a masonry wall generates a diagonal compressive stress flow towards the bottom corner of the wall and, consequently, leads to a flow of transversal tensile stresses. The addition of vertical reinforcements bonded to the masonry results on the increase of the transversal tensile stresses. As they prevents the uplift of the wall, they lead also to an earlier diagonal cracking. Noticed that the principal tensile stresses are considerably increased in the vicinity of the vertical reinforcements, as can be observed in see Fig. 17, where the distribution of the principal tensile stresses along the diagonal strut of wall is shown. The peaks on the principal tensile stresses are mainly localized at the upper and lower 
regions of the diagonal strut. The evolution of principal stresses is much smoother in unreinforced or lightly reinforced masonry walls. The result found in this work is in agreement with the one pointed out by Tomaževič [9], which stated that if vertical reinforcements are placed without the confinement of the horizontal reinforced are not able to contribute to the shear resistance. In fact, the masonry walls where only vertical reinforcement is applied can fail by shear diagonal cracking. From the results summarized in Table 4, it is also possible to observe that if unreinforced walls fail by shear, they continue to fail by shear after the addition of vertical reinforcement independently on the vertical reinforcement ratio.

For the highest level of pre-compression, for which the crushing of the bottom corners develops associated to high compressive stresses on masonry, the increase on the vertical reinforcement ratio increases the lateral strength, in spite of it is not very significant. In this case compression failure develops with the absence of diagonal cracking.

\section{Analysis 4 - Evaluation of the contribution of the vertical and horizontal reinforcement}

The parametric analysis includes also the assessment of influence of the combination of horizontal and vertical reinforcements on the lateral strength of masonry walls. The variation of the vertical and horizontal reinforcement ratio was performed by keeping the horizontal and vertical reinforcement constant, respectively. As in other cases, only 9 walls from the group of 25 specimens used in first study were considered for the variation of horizontal and vertical reinforcement ratios. Specimens with an 
aspect ratio of $h / L=1.00$ and selected variable compressive load levels and specimens with a constant pre-compression of $\sigma / f_{a}=0.20$ and the variable aspect ratios previously considered, were selected. In a first step, a constant vertical reinforcement ratio of 0.05\% was combined with three different horizontal reinforcement ratios: $0.03 \%, 0.05 \%$ and $0.08 \%$. In a second step, the horizontal reinforcement ratio of $0.05 \%$ was kept constant and was combined with three different vertical reinforcement ratios: $0.03 \%$, $0.05 \%$ and $0.08 \%$.

From the results it is possible to observe that in cantilever walls, when the vertical reinforcement ratio was kept constant and the horizontal reinforcement ratio varied, no changes in lateral strength occurred, which is attributed to the predominant flexural failure mode, similarly to what has been pointed out in case of the absence of vertical reinforcement. In case of fixed end walls, it is clear that the lateral strength is enhanced by the addition of horizontal reinforcement but no significant increase is recorded for increasing horizontal reinforcement ratios, see Fig. 18. Besides, the introduction of horizontal reinforcement changes the failure mode from shear to flexure in all evaluated specimens.

In masonry walls in which the horizontal reinforcement ratio was kept constant and equal to $0.05 \%$ and vertical reinforcement ratios were varied, the increase of the vertical reinforcement ratio improved the lateral strength of cantilever walls since flexure is the preponderant effect in this type of wall, see Fig. 19. On the other hand, in fixed end walls, which failed by shear, the variation of vertical reinforcement ratio produced small changes on the lateral behavior of masonry walls, see Fig.20. 


\section{Conclusions and final remarks}

In this work a numerical analysis was carried out in order to analyze the behavior of masonry walls subjected to lateral loading. Besides, the assessment of the influence of the several parameters on the lateral behavior of the masonry walls has been addressed. It should be mentioned that the output of the numerical parametric analysis was valuable to proceed with the analytical model for the design unreinforced and reinforced masonry walls under lateral loading, which was provided in Haach [19].

A micro-modeling approach was selected for the numerical simulation due to the need of understanding in detail the resisting mechanisms of masonry walls. The mechanical properties of materials used in the model were obtained from experimental tests on masonry materials. In a first phase the numerical model has been calibrated based on the experimental results of masonry walls tested under lateral cyclic loading. Very reasonable agreement was found between the numerical force-displacement diagrams and the monotonic experimental envelop describing the in-plane behaviour of masonry walls. In a second phase, an extensive parametric analysis has been performed aiming at assessing the influence of the aspect ratio, vertical pre-compression, horizontal and vertical reinforcement ratio on the in-plane behaviour of masonry walls. Concerning the results of numerical modeling of masonry walls the main following conclusions can be drawn:

(a) A failure surface based on the pre-compression and aspect ratio has been found indicating that walls with low aspect ratio and moderate pre-compression levels are more favourable to develop shear failure, whereas walls with high aspect ratios and low pre-compression levels are more favourable to develop flexure failure. On the other 
hand, it was observed that in cantilever walls flexure is preponderant, whereas in fixed end walls shear failure prevails on the in-plane response of the masonry walls.

(b) the influence of vertical reinforcement depends on the predominant resisting mechanism. Vertical reinforcement exhibited a small influence on the lateral resistance of walls when shear is the preponderant effect but it provided an enhancement on lateral strength when flexure governs the behaviour of the walls, since reinforcement resists tensile stresses due to the uplift of the wall.

(c) in case of horizontal reinforcement, its influence on the behaviour of shear walls depends on the preponderance of the resisting shear mechanisms. It was observed that horizontal reinforcement acts only after diagonal cracking, as observed in experiments. Besides, horizontal reinforcement provided a better distribution of stresses in the walls leading to a more distributed diagonal cracking. It was noticed the influence of horizontal reinforcement on the lateral resistance of cantilever walls is low due to the preponderant flexure mechanism.

Finally, it should be stressed that the output of the parametric study enabled the identification in more detail of the characteristic failure modes of masonry walls under in-plane loading. It enabled also to develop a design model to account for an appropriate contribution of the vertical and horizontal reinforcements to the lateral strength of the masonry walls which will be published in a subsequent paper.

\section{Acknowledgements}

This work was partly supported by contract DISWALL - “Development of innovative systems for reinforced masonry walls” - COOP-CT-2005-018120 from the European Commission. The first author was supported by the Programme Al $\beta$ an, the 
European Union Programme of High Level Scholarships for Latin America, Scholarship $n^{0}$ E06D100148BR. 


\section{References}

[1] Priestley, M.J.N.; Bridgeman D.O. (1974). "Seismic resistance of brick masonry walls”, Bull. Of the New Zealand Nat. Soc. for Earthquake Engineering, 7(4), 167-187.

[2] Tomaževič, M.; Zarnic, R. (1984). “The behaviour of horizontally reinforced masonry walls subjected to cyclic lateral in-plane loads reversals”, Proceedings of 8th European Conference on Earthquake Engineering, Lisbon, Portugal, V.4, 9pp.

[3] Shing, P. B.; Schuller, M.; Hoskere, V. S. (1990). "In-Plane resistance of reinforced masonry shear walls”, Journal of Structural Engineering, 116(3), 619-640.

[4] Mahmoud, A.D.S.; Hamid, A.A.; El Mags, S. A. (1995). “Lateral response of unreinforced solid masonry shear walls: an experimental study”, Proceedings of 7th Canadian Masonry Symposium, Hamilton, Ontario, Canada, 110-125.

[5] Zhuge, Y.; Corderoy, J.; Thambiratnam, D. (1996). “Behavior of unreinforced brick masonry under lateral (cyclic) loading”, TMS Journal, 14(2), 55-62.

[6] Magenes G and Calvi GM (1997), In-plane seismic response of brick masonry walls, Earthquake Engineering and Structural Dynamics, John Wiley \& Sons, 26(11), 10911112.

[7] Magenes G, (1998), In-plane cyclic testing of reinforced masonry shear walls, Proceedings of $11^{\text {th }}$ European Conference on Earthquake Engineering, Balkema, Rotterdam, Netherlands.

[8] Schultz, A.E.; Hutchinson; R.S., Cheok, G.C. (1998). “Seismic performance of masonry walls with bed joint reinforcement”, Proceedings of Structural Engineers World Congress, San Francisco, California, USA, paper nº 40.

[9] Tomaževič, M. (1999). "Earthquake-resistant design of masonry buildings”, Imperial College Press, London. 
[10] Bosiljkov, V.; Page, A., Bokan-Bosiljkov, V., Žarnić, R. (2003). “Performance based studies of in-plane loaded unreinforced masonry walls”, Masonry International, 16(2), 39-50.

[11] Yoshimura, K., Kikuchi, K., Kuroki, M., Nonaka, H., Kim, K.T., Matsumoto, Y. Itai, T., Reeznag, W., Ma, L. (2003). “Experimental study on reinforcing methods for confined masonry walls subjected to seismic forces”, Proceedings of 9th North American Masonry Conference, Clemson, South Carolina, USA, 89-100.

[12] Vasconcelos, G. (2005). “Experimental investigations on the mechanics of stone masonry: Characterization of granites and behaviour of ancient masonry shear walls”, PhD Thesis, University of Minho, Guimarães, Portugal. Available from www.civil.uminho.pt/masonry.

[13] Voon, K.C., Ingham, J.M. (2006). “Experimental in-plane shear strength investigation of reinforced concrete masonry walls”, Journal of Structural Engineering, 132(3), 400-408.

[14] Steelman, J.; Abrams, D. P. (2007). “Effect of axial stress and aspect ratio on lateral strength of URM shear walls”, Proceedings of 10th North American Masonry Conference, St. Louis, Missouri, USA, 849-859.

[15] Mosele F, da Porto F, Dalla Benetta M, Modena C (2008). Experimental behaviour of newly developed system for load-bearing reinforced masonry walls. Proceedings of 14th International Brick and Block Masonry Conference, Sydney, Australia.

[16] ESECMaSE project (2004-2007), Enhanced Safety and Efficient Construction of Masonry Structures in Europe, COLLCT-2003-500291.

[17] DISWall project (2006-2008), Developing innovative systems for Reinforced Masonry Walls, COOPCT-2005-018120. 
[18] Lourenço, P.B.; Rots, J.G.; Blaauwendraad, J. (1998) “Continuum model for masonry: Parameter estimation and validation”, Journal of Structural Engineering, 124(6), 642-652.

[19] Lourenço, P.B.; Rots, J.G. (1997) “Multisurface interface model for analysis of masonry structures”, Journal of Engineering Mechanics, 123(7), 660-668.

[20] El-Dakhakhni, W.W., Drysdale, R.G.; Khattab, M.M. (2006). "Multilaminate Macromodel for Concrete Masonry: Formulation and Verification", Journal of Structural Engineering, 132(12), 1984-1996.

[21] Gambarota, L.; Lagomarsino, S.. "Damage models for the seismic response of brick masonry shear walls. Part II: The continuum model and its applications”, Earthquake engineering and structural dynamics, 26, 1997, 441-462.

[22] Asteris, P.G.; Tzamtzis, A.D. (2003). “On the Use of a Regular Yield Surface for the Analysis of Unreinforced Masonry Walls”, Electronic Journal Of Structural Engineering, V.3, pp.23-42.

[23] Sutcliffe, D. J.; Yu, H. S.; Page, A. W. (2001). "Lower bound limit analysis of unreinforced masonry shear walls”, Computers \& Structures, 79(14), 1295-1312. [24] Chaimoon, K.; Attard, M.M. (2007). “Modeling of unreinforced masonry walls under shear and compression”, Engineering structures, V.29(3), 2056-2068.

[25] Haach, V.G.; Vasconcelos, G.; Lourenço, P. B (2010). “Experimental analysis of reinforced concrete block masonry walls subjected to in-plane cyclic loading”, Journal of Structural Engineering, V. 136(4), 452-462.

[26] Haach, V.G. (2009). "Development of a design method for reinforced masonry subjected to in-plane loading based on experimental and numerical analysis”, $\mathrm{PhD}$ 
Thesis, University of Minho, Guimarães, Portugal. Available from www.civil.uminho.pt/masonry.

[27] Vasconcelos, G., Lourenço, P.B. (2009), “In-plane experimental behaviour of stone masonry walls under cyclic loading”, Journal of Structural Engineering, V. 135(10), 1269-1277.

[28] EUROPEAN STANDARD. EN 1996-1-1, Eurocode 6: Design of masonry structures, 2005.

[29] Mohamad, G. (2007). “Mechanism failure of concrete block masonry under compression”, PhD Thesis, University of Minho, Guimarães, Portugal (In Portuguese). Available from www.civil.uminho.pt/masonry.

[30] Van Zijl, G.P.A.G. (2004). “Modeling masonry shear-compression: Role of Dilatancy highlighted”, Journal of engineering mechanics, 30(11), 1289-1296.

[31] Vasconcelos, G., Lourenço, P.B., Haach, V.G. (2008). “Avaliação experimental da aderência de juntas de alvenaria de blocos de betão”, Proceedings of $7^{\circ}$ Congresso Nacional de Mecânica Experimental, Vila Real, Portugal, 101-103. (in Portuguese) [32] Anthoine, A., Magonette, G., Magenes, G. (1995). "Shear-compression testing and analysis of brick masonry walls”, Proceedings of 10th European Conference on Earthquake Engineering, Balkema, Rotterdam, Netherlands.

[33] Schultz, A.E., Hutchinson, R.S., Cheok, G.C. (1998). “Seismic performance of masonry walls with bed joint reinforcement”, Proceedings of Structural Engineers World Congress, San Francisco, California, USA, paper nº 40.

[34] Kikuchi, K., Yoshimura, K., Tanaka, A., Yoshida, K. (2003). "Effect of wall aspect ratio on seismic behaviour of reinforced fully grouted concrete masonry walls”, 
Proceedings of 9th North American Masonry Conference, Clemson, South Carolina, USA, 214-225.

[35] Drysdale, R.G., Hamid, A.A., Baker, L.R. (1999). “Masonry structures: behaviour and design”, The Masonry Society, Boulder, Colorado, USA. 


\section{List of captions for illustrations}

Fig. 1 - Test setup used in experiments.

Fig. 2 - Elements used in numerical modeling.

Fig. 3 - Example of mesh applied to the shear walls.

Fig. 4 - Mechanical behavior of the units used in numerical modeling: (a) tension, (b) compression and (c) shear (DIANA ${ }^{\circledR}$ ).

Fig. 5 - Reinforcement stiffness in interface (DIANA ${ }^{\circledR}$ ).

Fig. 6 - Validation of numerical results (Force vs. displacement diagrams): (a) N60UM, (b) N60-SH, (c) N60, (d) N150, (e) N60 -MA and (f) N60 -PA.

Fig. 7 - Limit states detected by the numerical modeling (Principal stresses).

Fig. 8 - Validation of numerical results (strain in reinforcements): (a) horizontal reinforcement and (b) vertical reinforcement.

Fig. 9 - Influence of aspect ratio in lateral strength of shear-walls: (a) cantilever wall and (b) fixed end wall.

Fig. 10 - Influence of pre-compression in lateral strength of shear-walls: (a) cantilever wall and (b) fixed end wall.

Fig. 11 - Failure surface of unreinforced shear-walls: (a) cantilever wall and (b) fixed end wall.

Fig. 12 - Influence of the horizontal reinforcement in cantilever walls (lateral strength vs. pre-compression).

Fig. 13 - Influence of the horizontal reinforcement in fixed end walls (lateral strength vs. pre-compression).

Fig. 14 - Control of cracking provided by horizontal reinforcements: (a) unreinforced masonry wall and (b) horizontally reinforced masonry wall. (Deformed mesh with the 
representation of the principal stresses of the numerical modeling after the application of a lateral displacement equal to $5 \mathrm{~mm}$ ).

Fig. 15 - Influence of the vertical reinforcement in cantilever walls (lateral strength vs. pre-compression).

Fig. 16 - Influence of the vertical reinforcement in fixed end walls (lateral strength vs. pre-compression).

Fig. 17 - Premature cracking in masonry walls with vertical reinforcements alone. Fig. 18 - Influence of the horizontal reinforcement with the vertical reinforcement constant (0.05\%) in fixed end walls (lateral strength vs. pre-compression).

Fig. 19 - Influence of the vertical reinforcement with the horizontal reinforcement constant $(0.05 \%)$ in cantilever walls (lateral strength vs. pre-compression).

Fig. 20 - Influence of the vertical reinforcement with the horizontal reinforcement constant (0.05\%) in fixed end walls (lateral strength vs. pre-compression). 

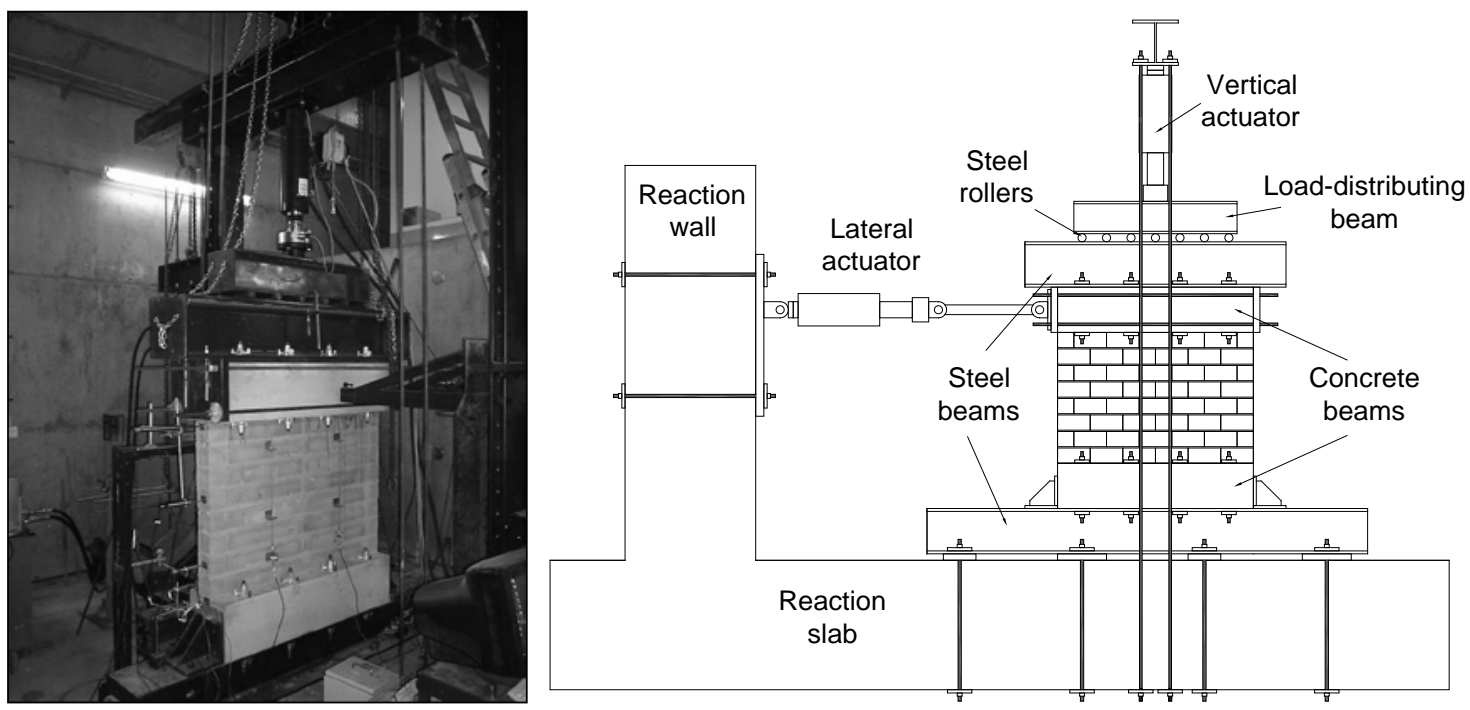


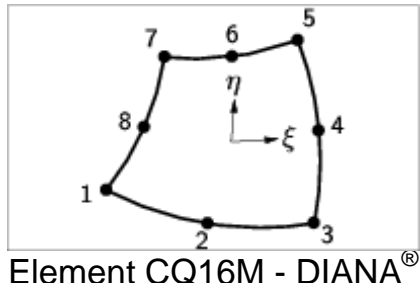

Element CQ16M - DIANA ${ }^{\circledR}$

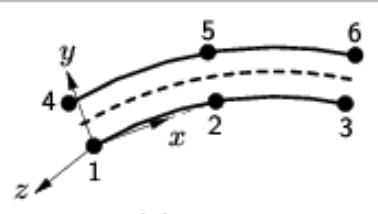

(a) topology

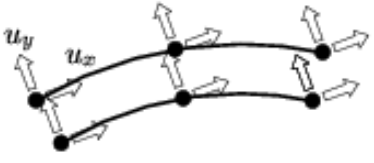

(b) displacements Element CQ16M - DIANA ${ }^{\circledR}$ 


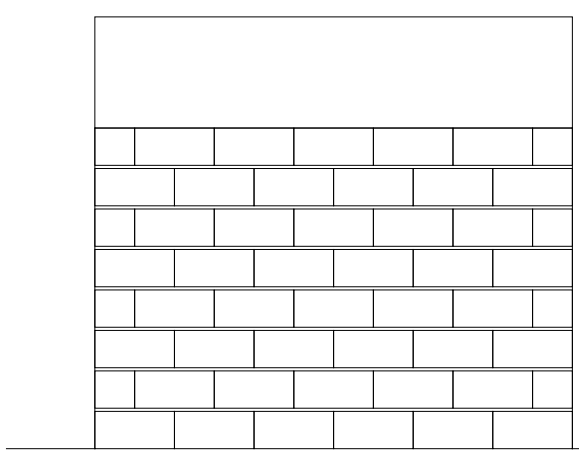

WALL

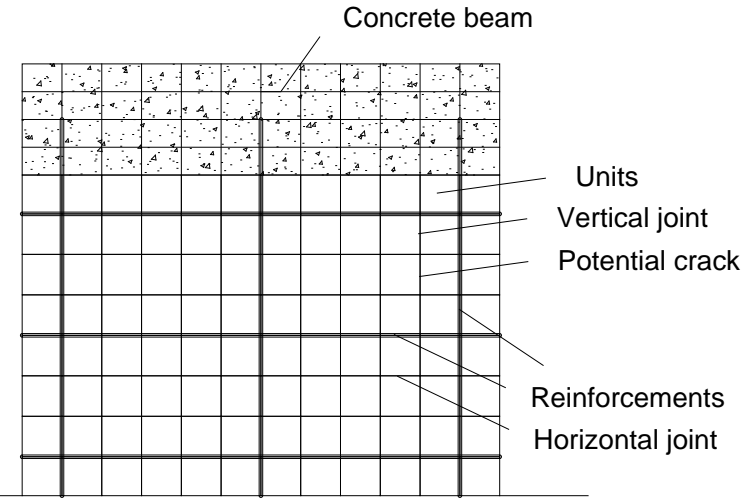

MESH

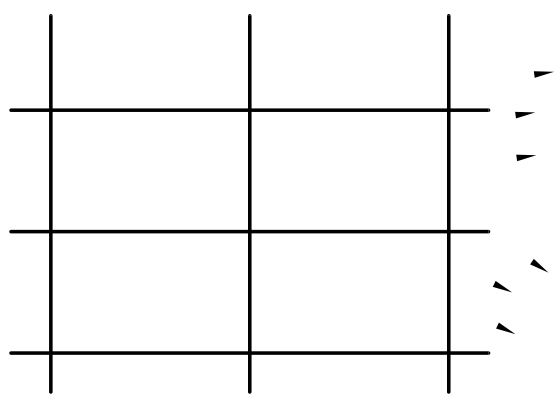




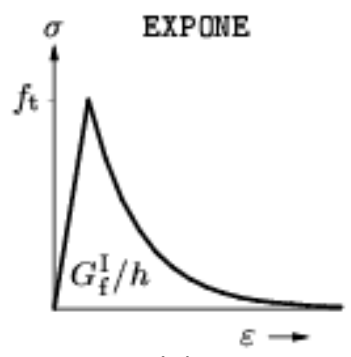

(a)

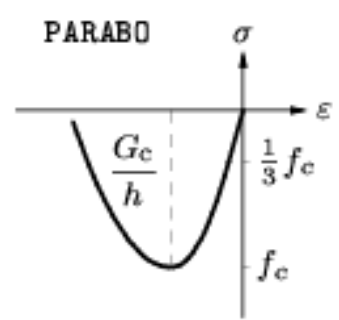

(b)

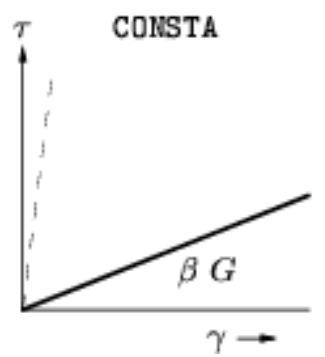

(c) 


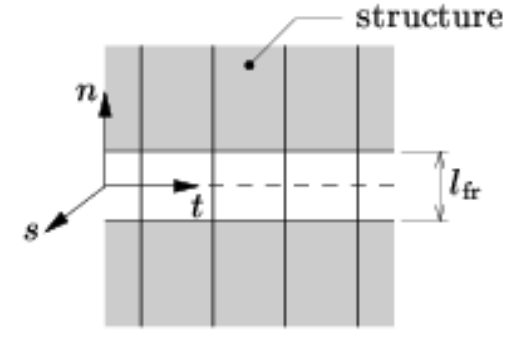

(a) free length

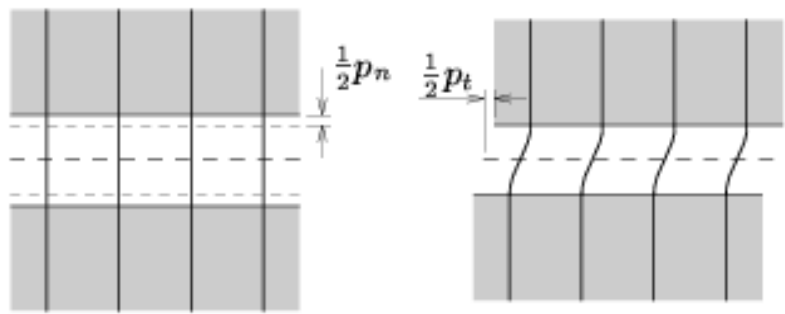

(b) normal deformation

(c) shear deformation 


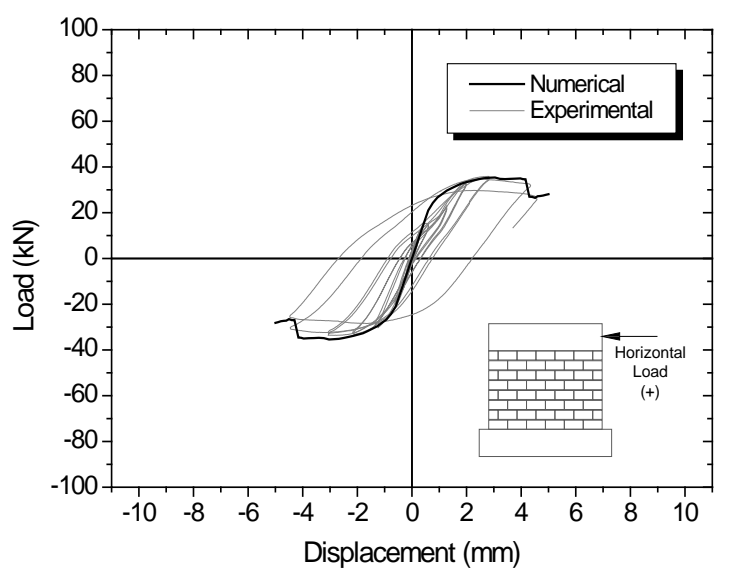

(a)

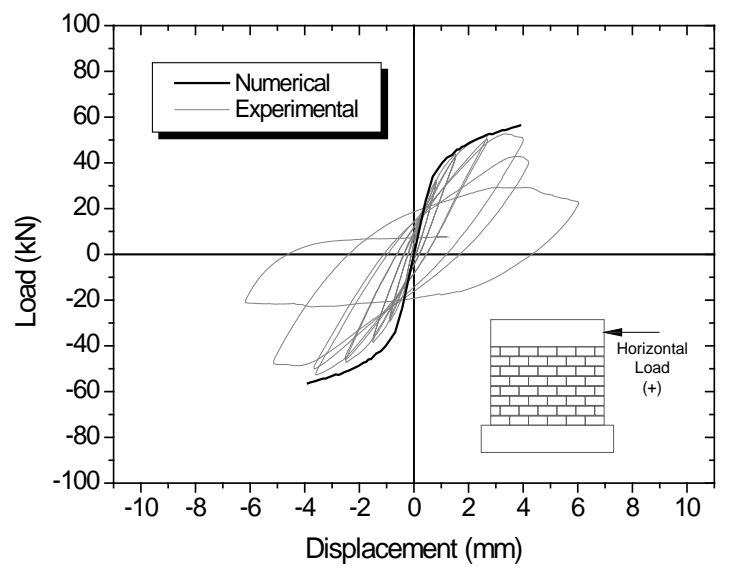

(c)

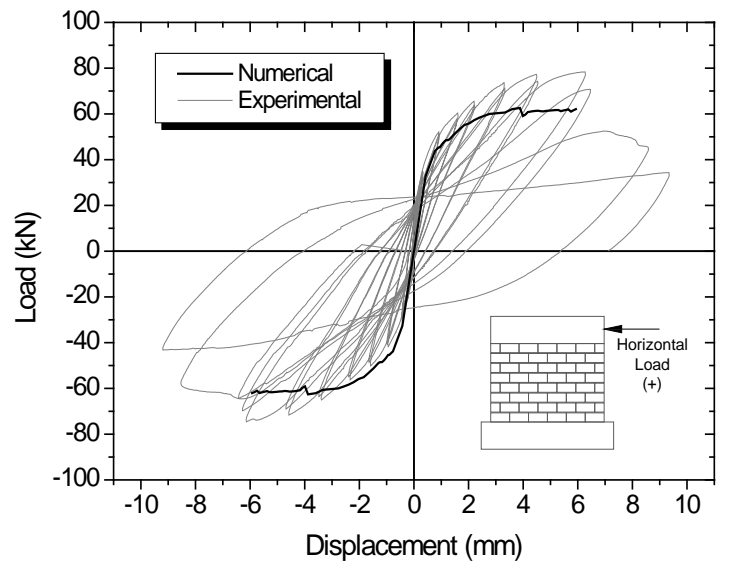

(e)

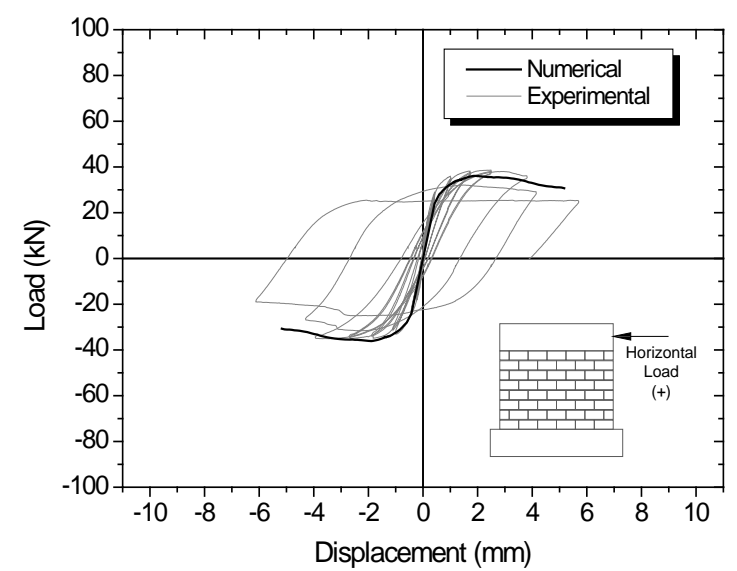

(b)

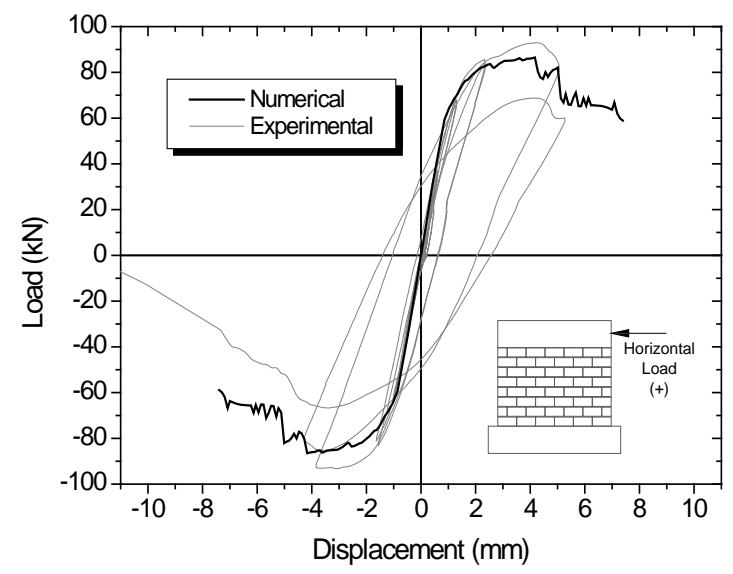

(d)

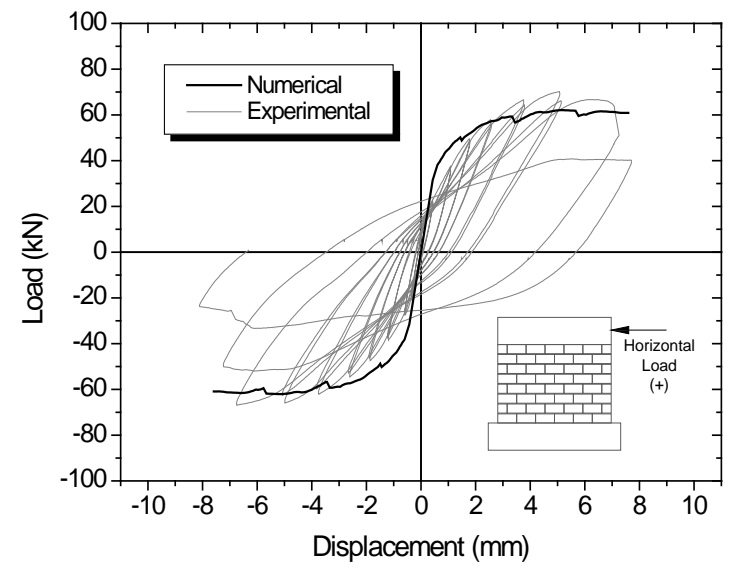

(f) 


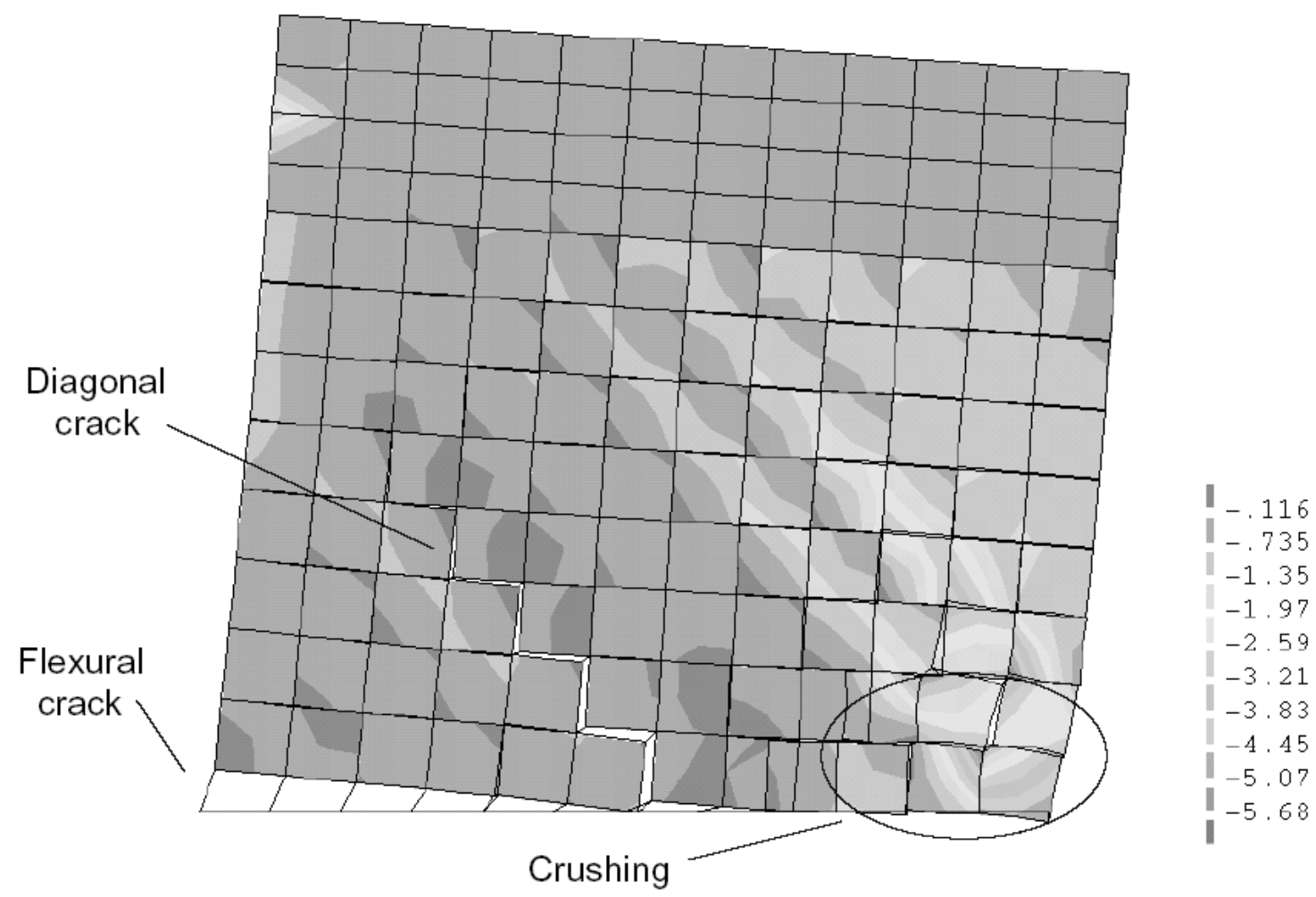




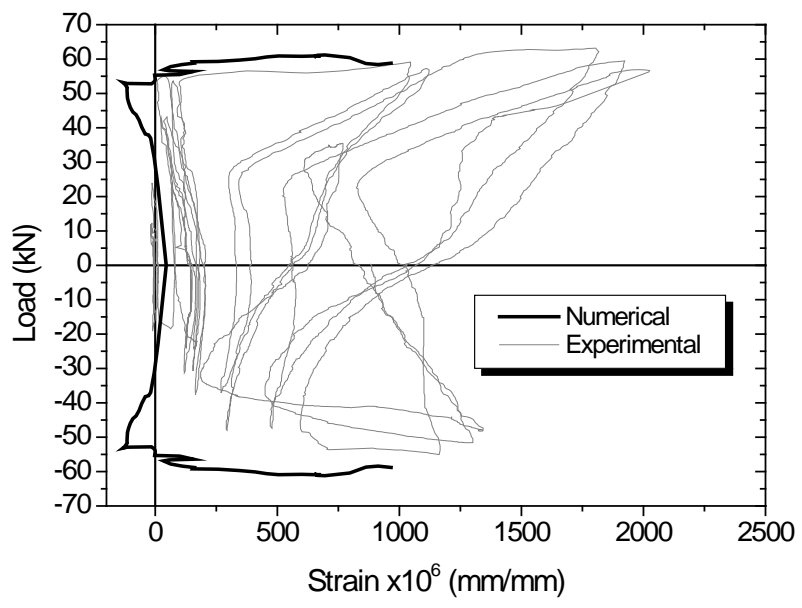

(a)

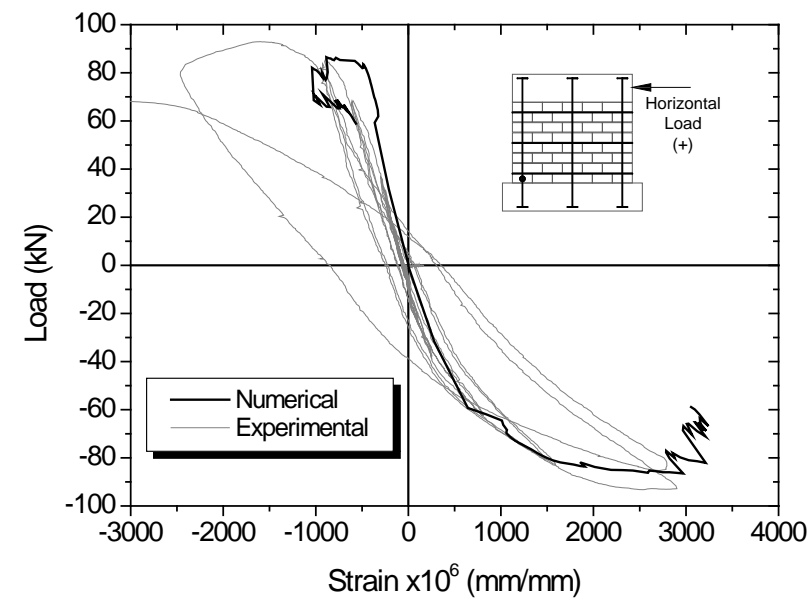

(b) 


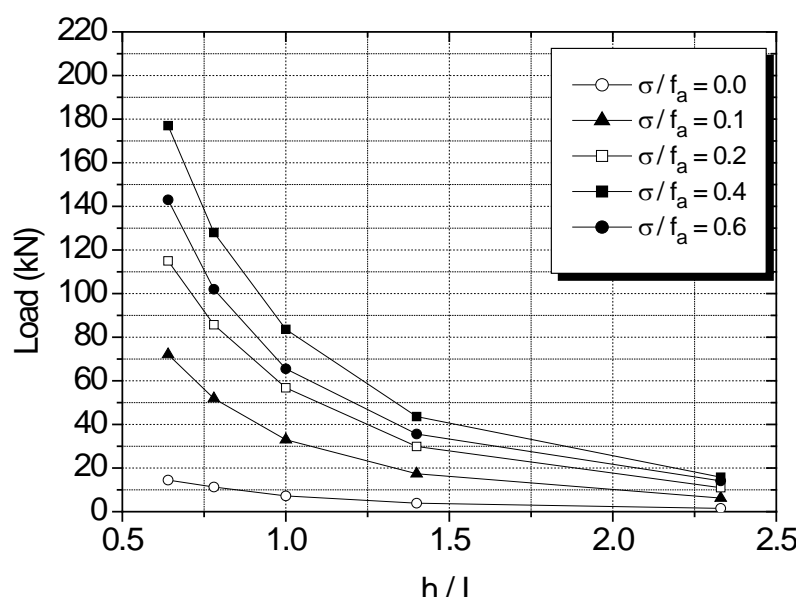

(a)

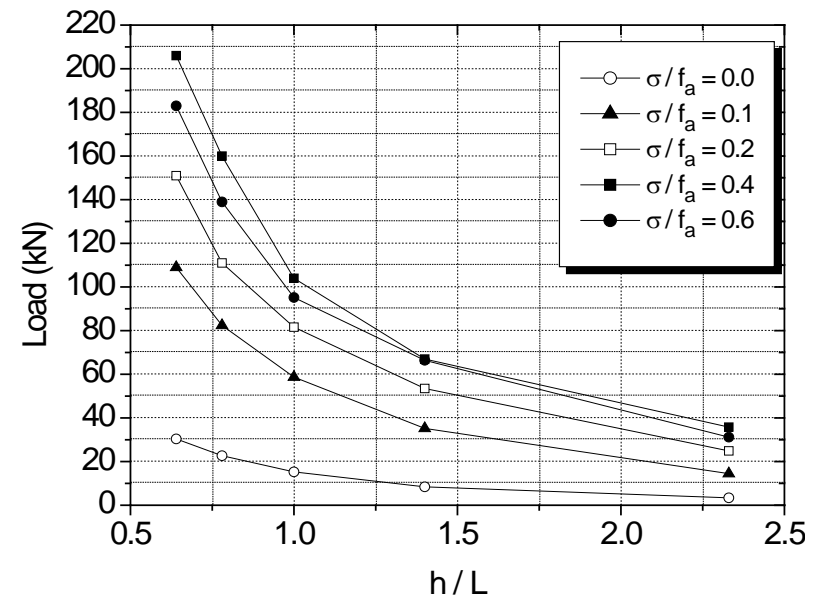

(b) 


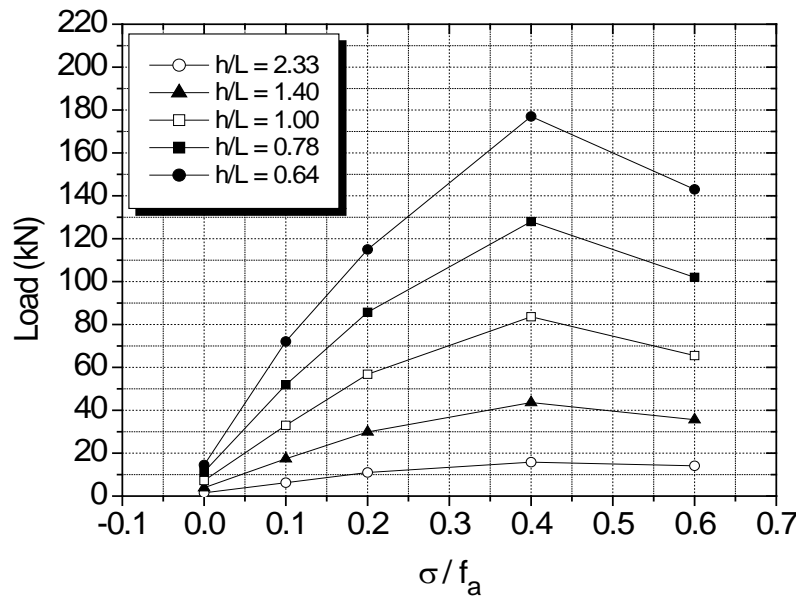

(a)

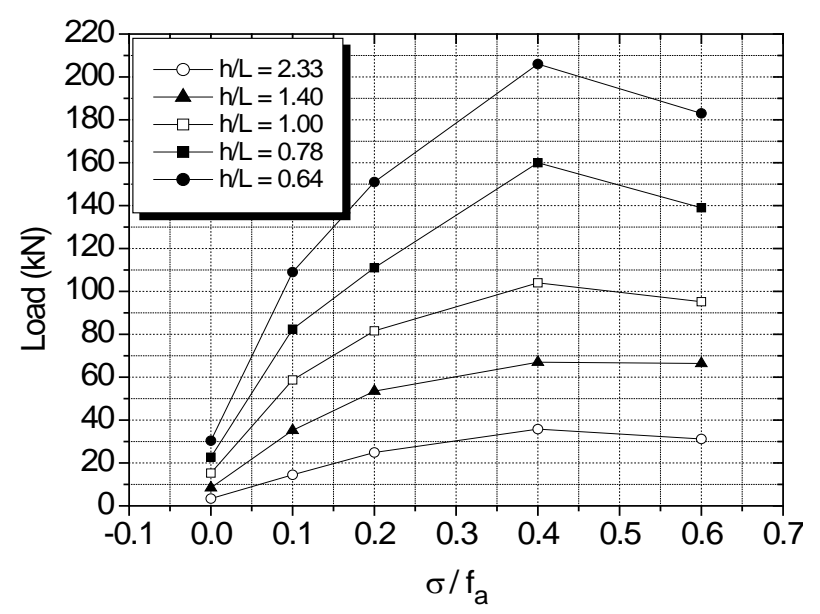

(b) 


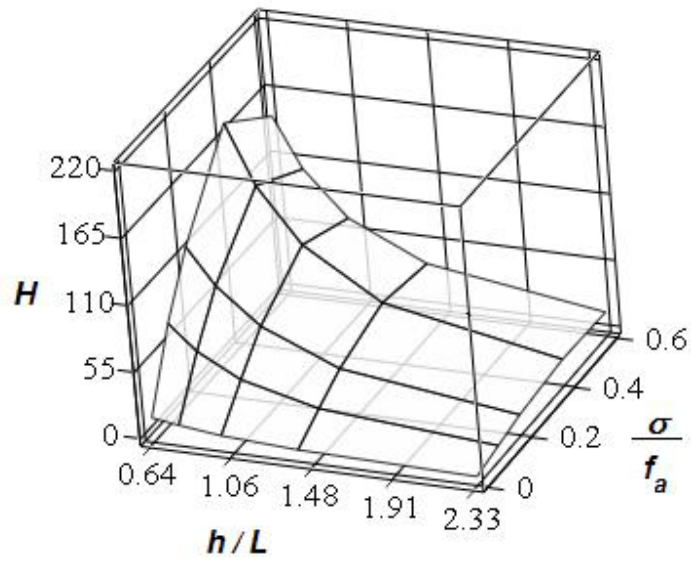

(a)

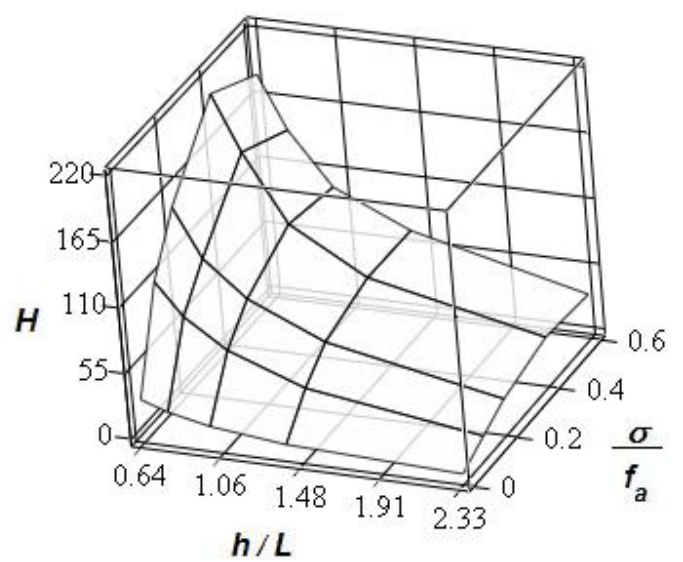

(b) 


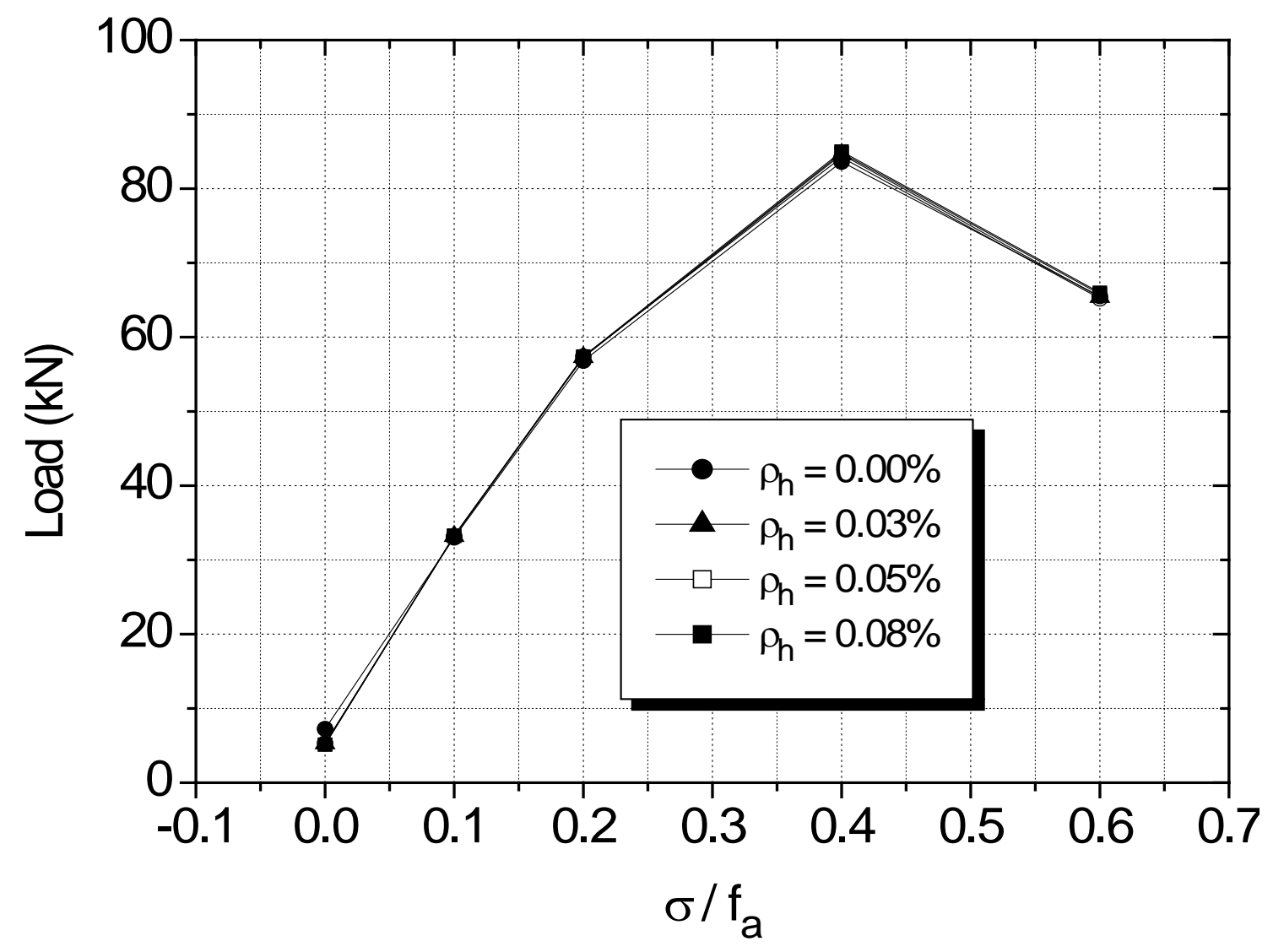




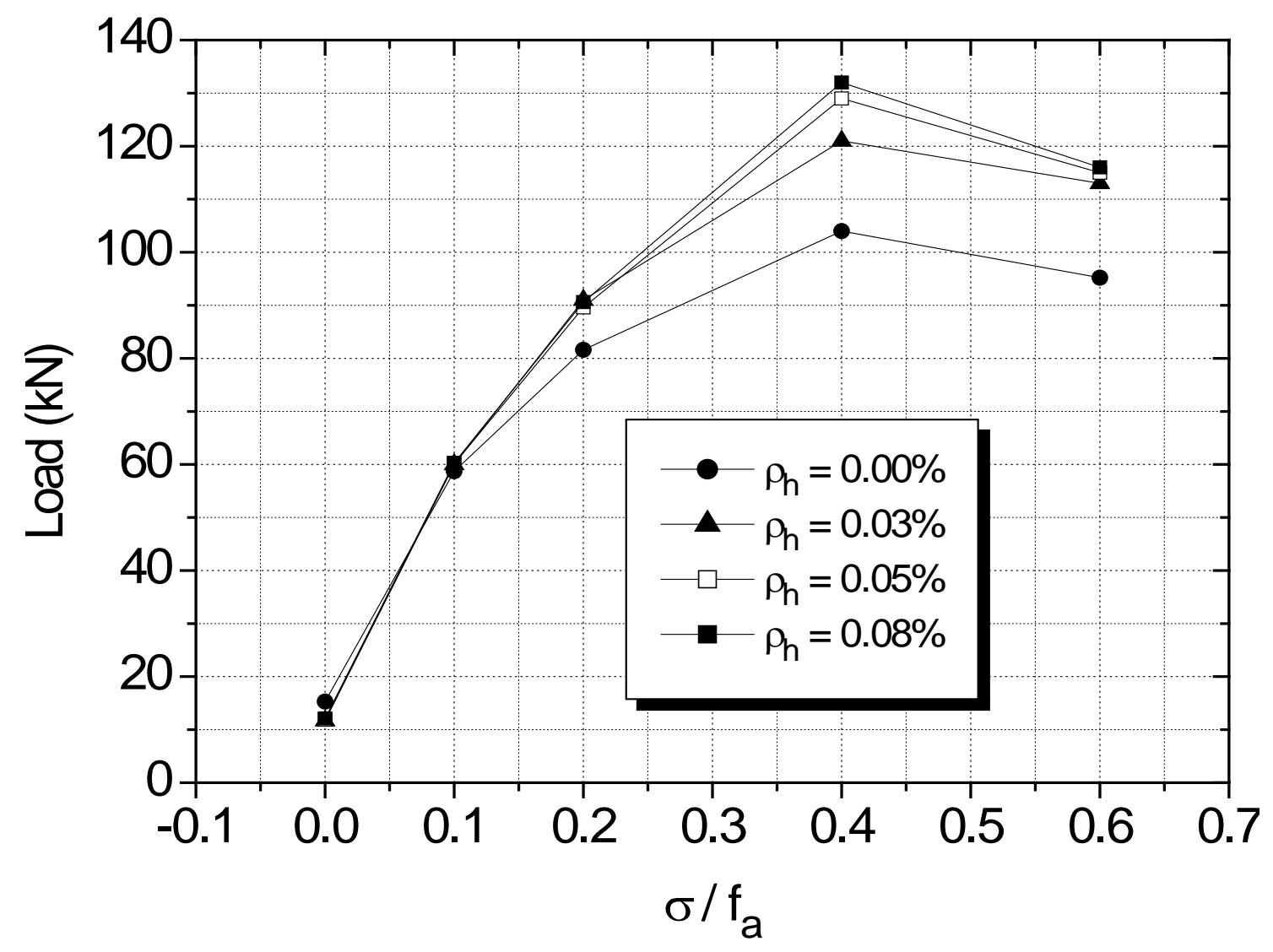




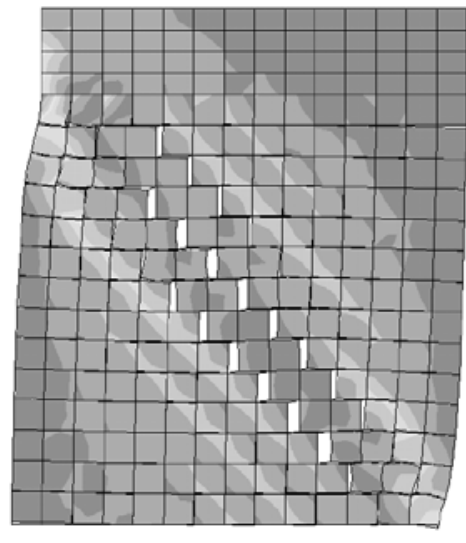

(a)

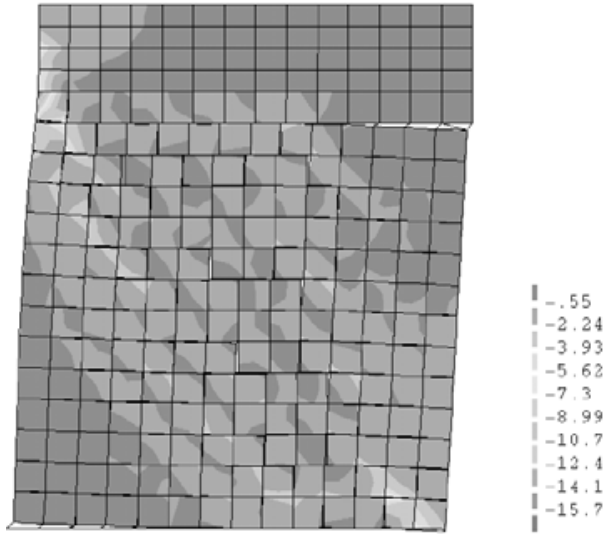

(b) 


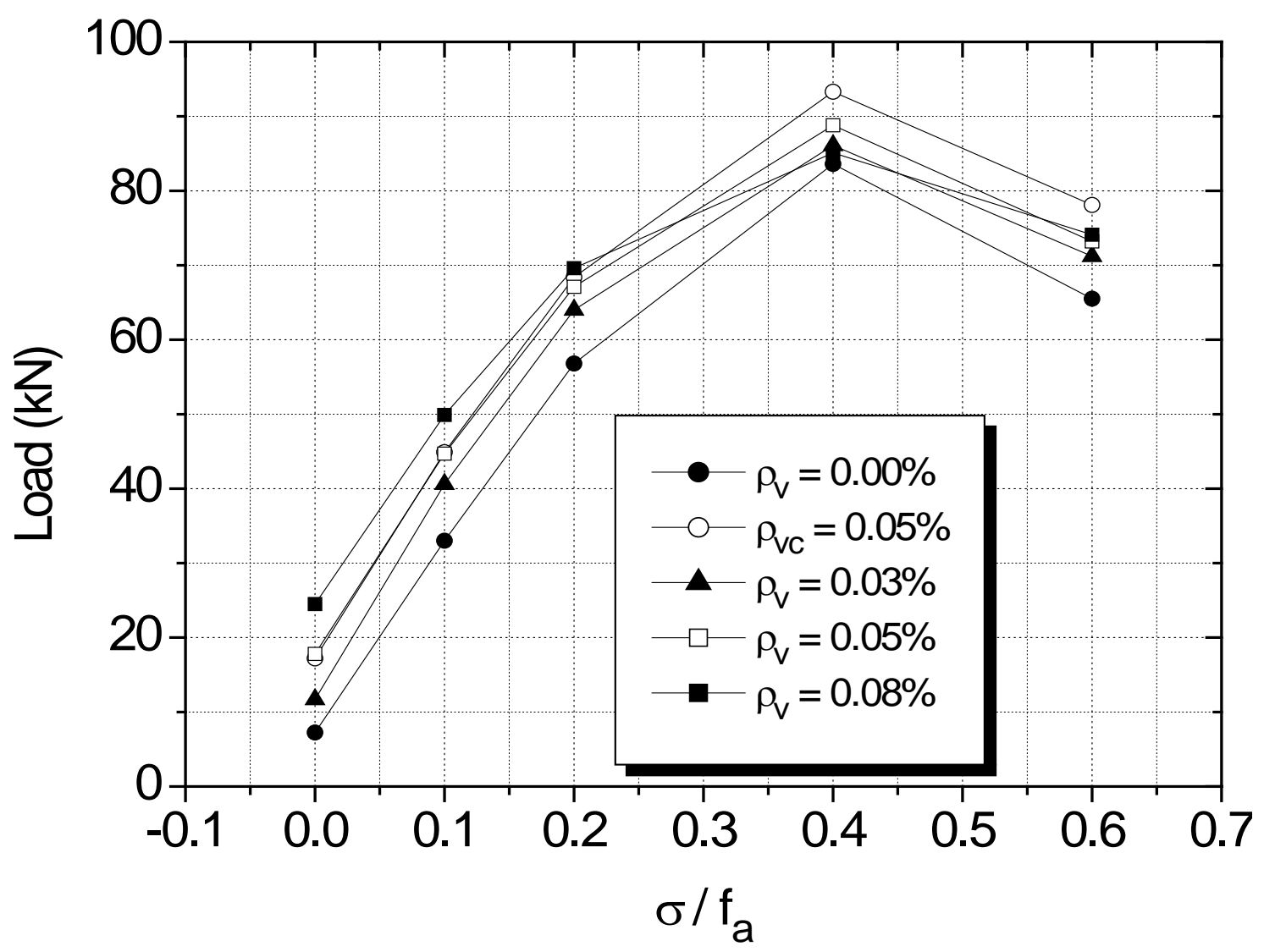




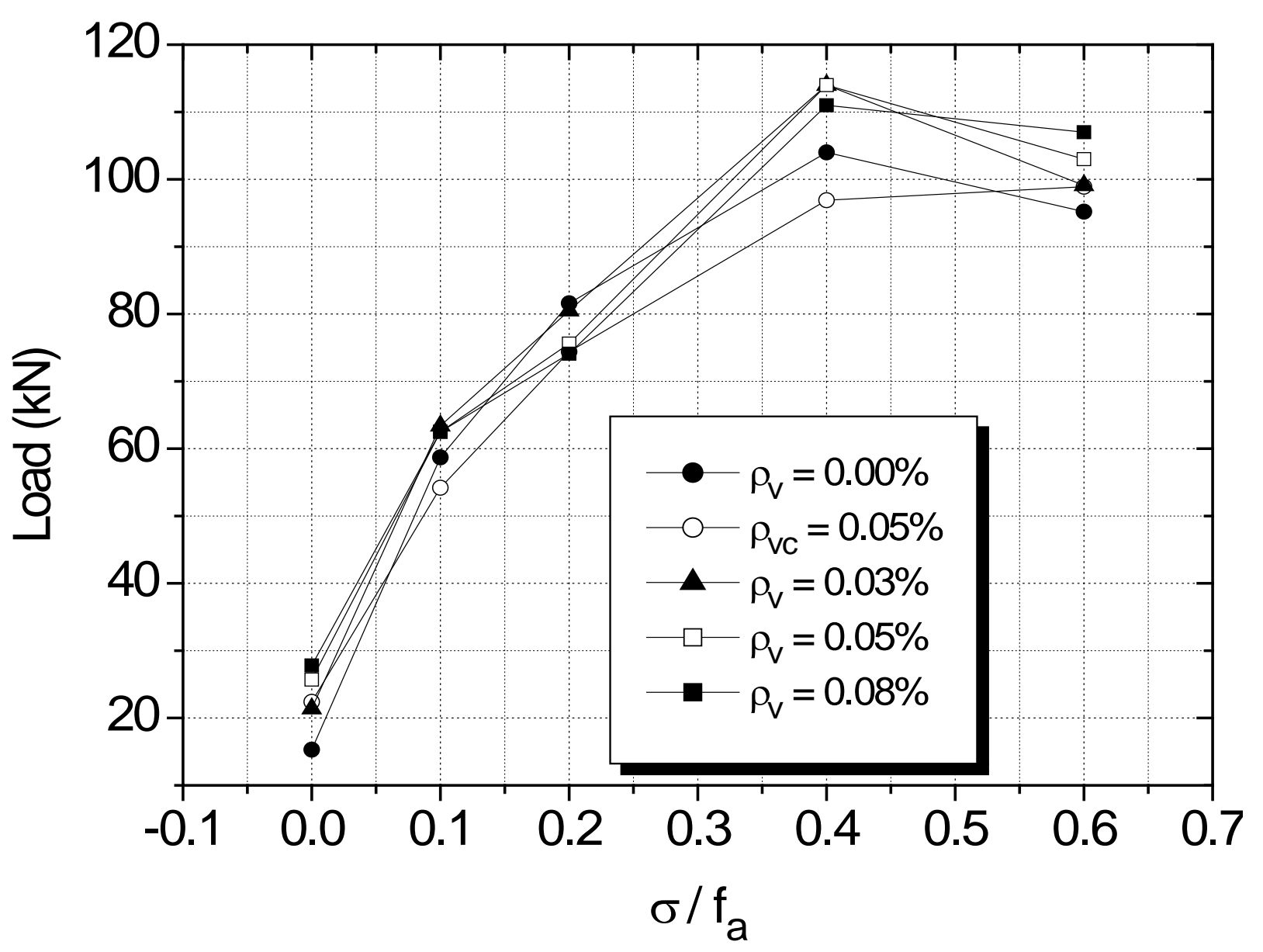



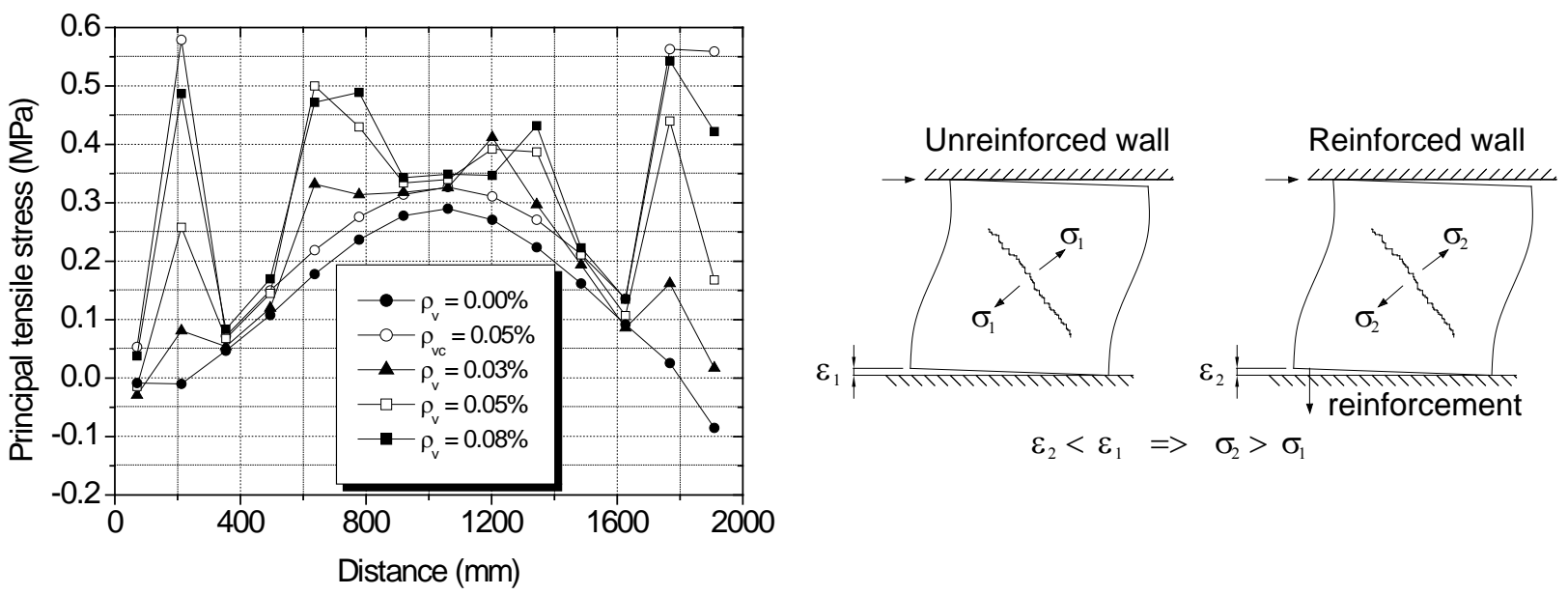


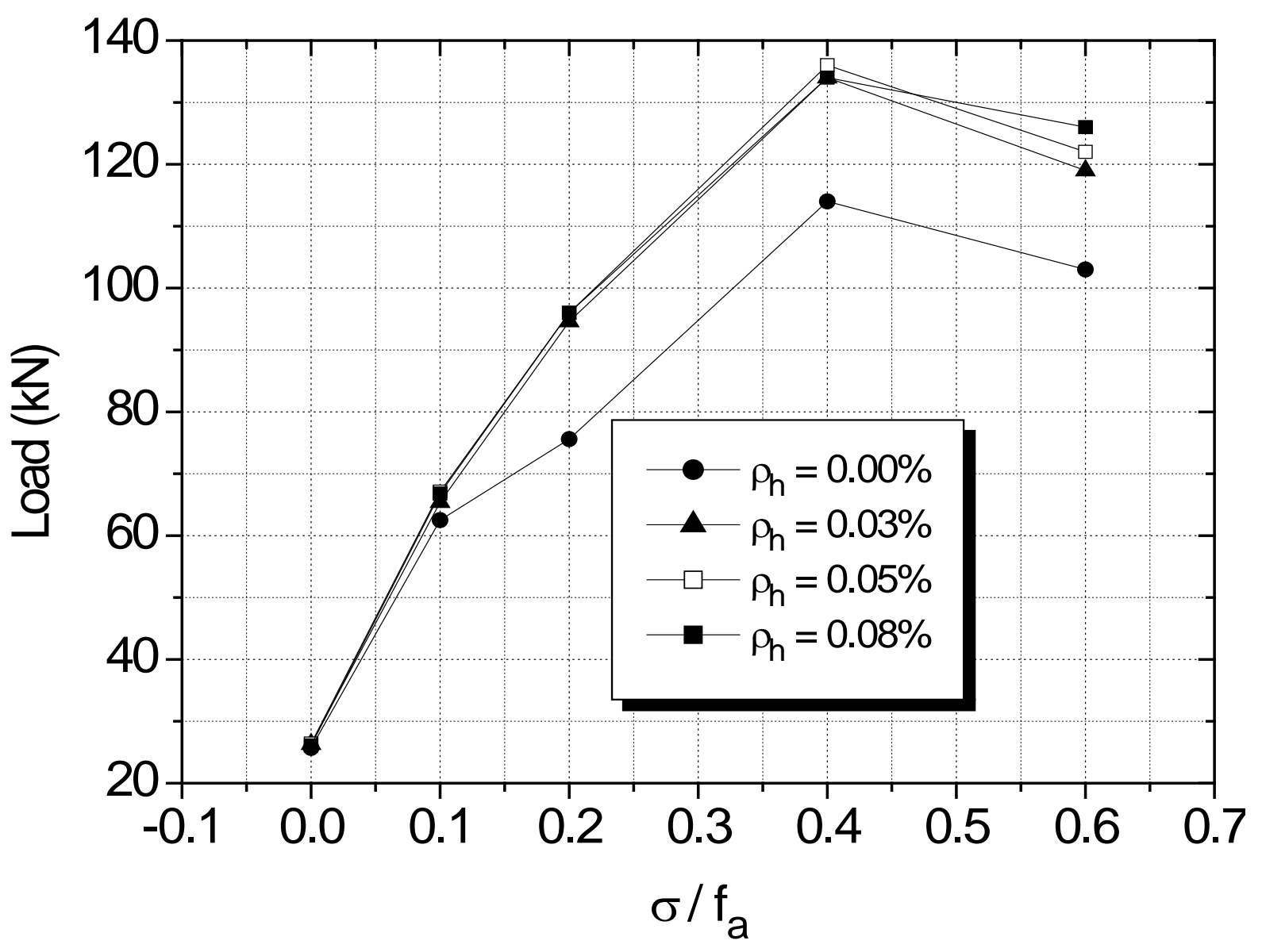




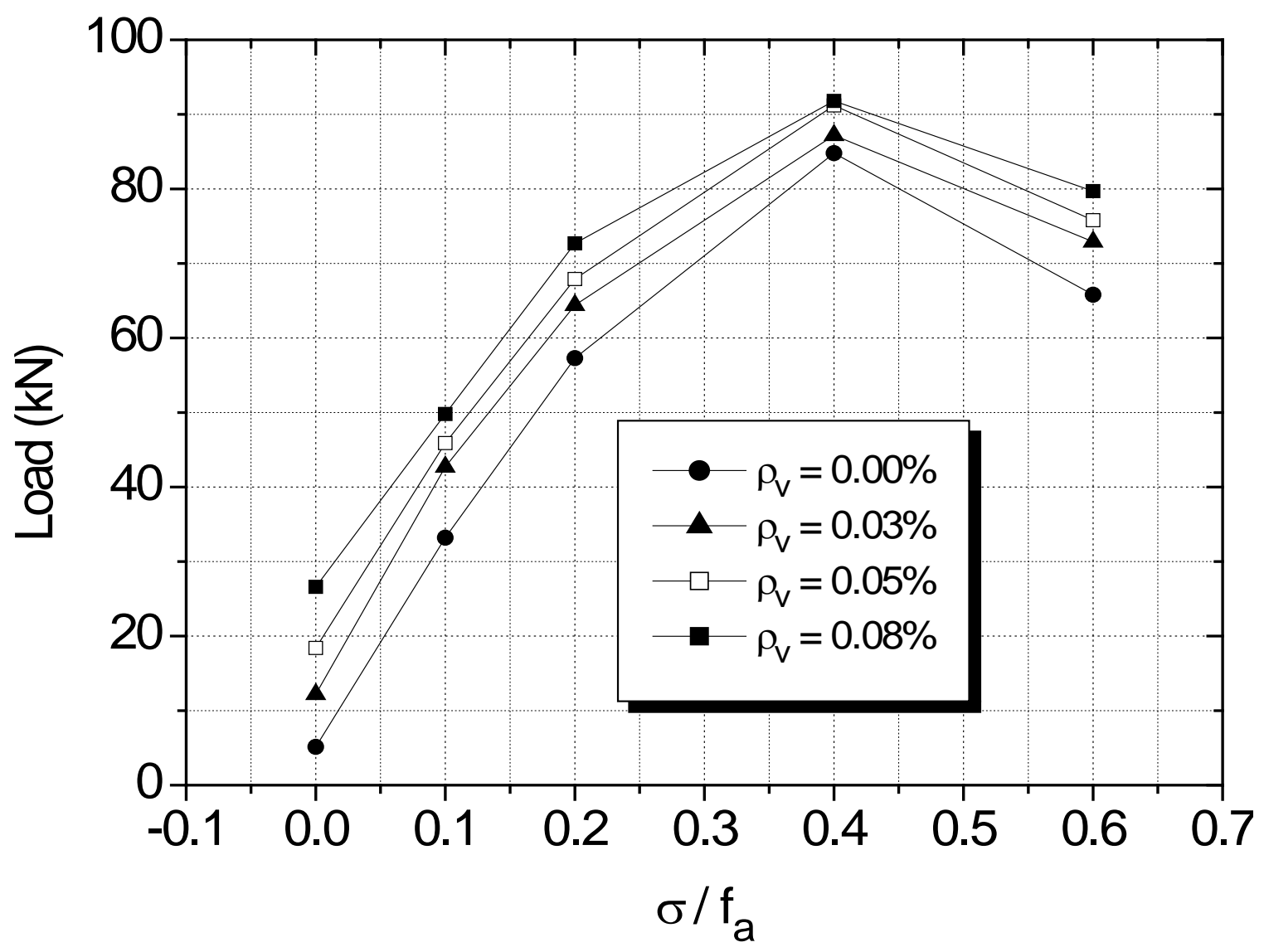




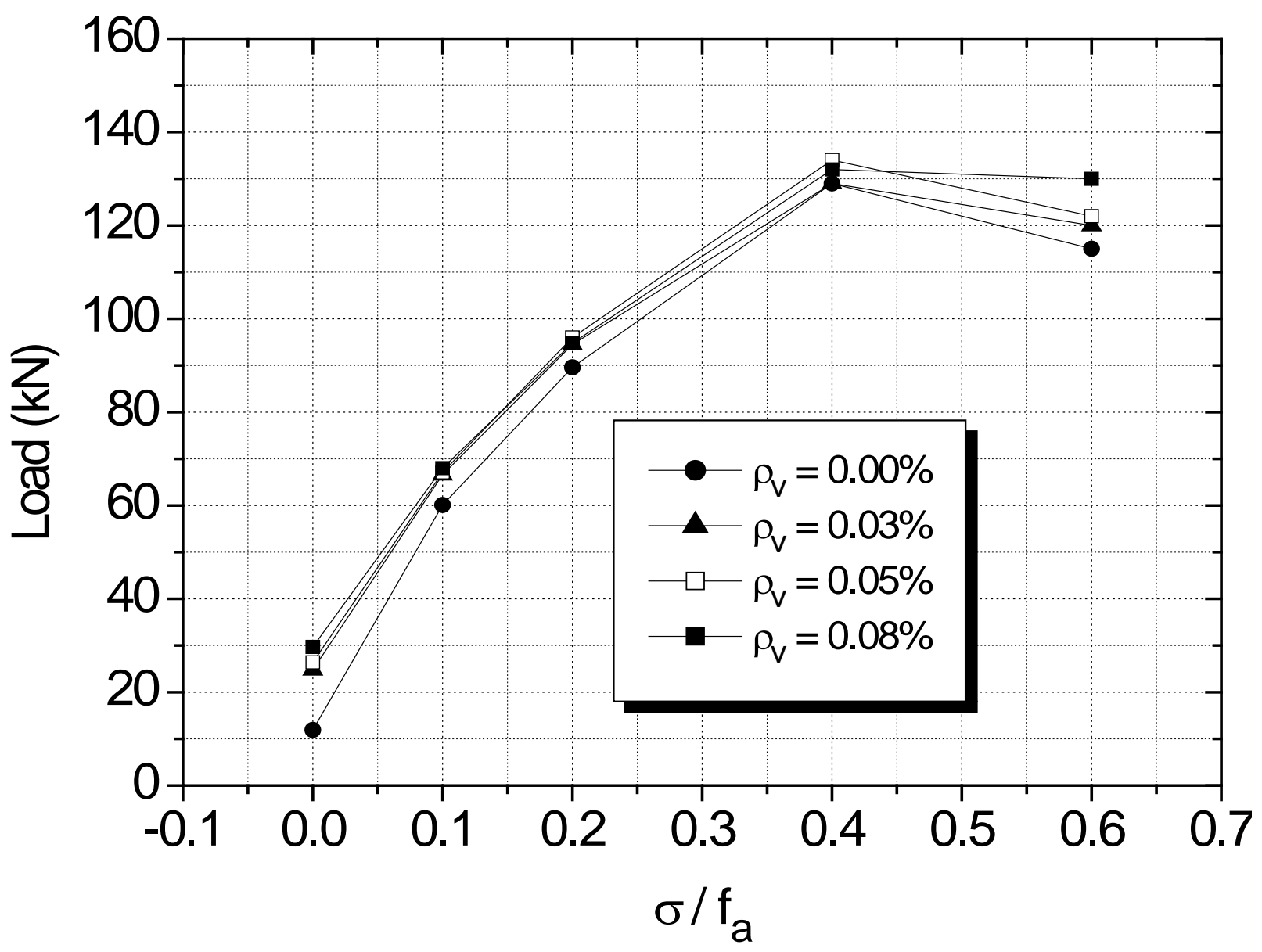


Table 1 - Details of the concrete masonry wall specimens (Haach et al. [25]).

\begin{tabular}{ccccc}
\hline Wall & $\begin{array}{c}\boldsymbol{\rho}_{\mathrm{v}} \\
(\%)\end{array}$ & $\begin{array}{c}\rho_{\mathrm{h}} \\
(\%)\end{array}$ & $\begin{array}{c}\text { Dimensions } \\
(\mathrm{mm})\end{array}$ & $\begin{array}{c}\text { Pre-Compression } \\
(\mathrm{MPa})\end{array}$ \\
\hline N60-UM & - & - & $1206 \times 800 \times 100$ & 0.56 \\
\hline $\mathrm{N} 150$ & 0.098 & 0.094 & $1206 \times 800 \times 100$ & 1.30 \\
\hline N60 & 0.098 & 0.094 & $1206 \times 800 \times 100$ & 0.56 \\
\hline N60-SH & - & 0.094 & $1206 \times 800 \times 100$ & 0.56 \\
\hline N60-PA & 0.098 & 0.053 & $1206 \times 800 \times 100$ & 0.56 \\
\hline N60-MA & 0.098 & 0.126 & $1206 \times 800 \times 100$ & 0.56 \\
\hline
\end{tabular}


Table 2 - Failure modes of unreinforced shear walls in numerical modeling (cantilever/fixed end).

\begin{tabular}{|c|c|c|c|c|c|}
\hline $\mathrm{f}_{\mathrm{a} / \mathrm{L}}$ & 0.0 & 0.1 & 0.2 & 0.4 & 0.6 \\
\hline 2.33 & FL (R) / FL (R) & FL (R) / FL (R) & FL (R) / FL (R) & FL (R) / FL (R) & $\mathrm{FL}(\mathrm{R}) / \mathrm{FL}(\mathrm{R})$ \\
\hline 1.40 & FL (R) / FL (R) & FL (R) / SH & $\mathrm{FL}(\mathrm{R}) / \mathrm{SH}$ & $\mathrm{FL}(\mathrm{R}) / \mathrm{SH}$ & $\mathrm{FL}(\mathrm{R}) / \mathrm{SH}$ \\
\hline 1.00 & FL (R) / FL (R) & FL (R) / SH & FL (R) / SH & FL (C) / SH & FL (C) / SH \\
\hline 0.78 & FL (R) / FL (R) & $\mathrm{SH} / \mathrm{SH}$ & $\mathrm{SH} / \mathrm{SH}$ & $\mathrm{SH} / \mathrm{SH}$ & FL (C) / SH \\
\hline 0.64 & FL (R) / FL (R) & $\mathrm{SH} / \mathrm{SH}$ & $\mathrm{SH} / \mathrm{SH}$ & $\mathrm{SH} / \mathrm{SH}$ & FL (C) / SH \\
\hline
\end{tabular}


Table 3 - Failure modes of reinforced shear walls with variation of horizontal reinforcement (cantilever/ fixed end).

\begin{tabular}{|c|c|c|c|c|c|}
\hline & \multicolumn{5}{|c|}{$\sigma / f_{a}=0.2$} \\
\hline$\rho(\%)$ & 2.33 & 1.40 & 1.00 & 0.78 & 0.64 \\
\hline 0.00 & FL (R) / FL (R) & FL (R) / SH & $\mathrm{FL}(\mathrm{R}) / \mathrm{SH}$ & $\mathrm{SH} / \mathrm{SH}$ & $\mathrm{SH} / \mathrm{SH}$ \\
\hline 0.03 & FL (R) / FL (R) & FL (R) / SH & FL (R) / SH & FL (C) / SH & FL (C) / SH \\
\hline 0.05 & FL (R) / FL (R) & FL (R) / M & FL (R) / M & $\mathrm{FL}(\mathrm{C}) / \mathrm{M}$ & $\overline{\mathrm{FL}}(\mathrm{C}) / \mathrm{SH}$ \\
\hline \multirow[t]{2}{*}{0.08} & FL (R) / FL (R) & $\mathrm{FL}(\mathrm{R}) / \mathrm{M}$ & $\mathrm{FL}(\mathrm{R}) / \mathrm{M}$ & $\mathrm{FL}(\mathrm{C}) / \mathrm{M}$ & $\mathrm{FL}(\mathrm{C}) / \mathrm{M}$ \\
\hline & \multicolumn{5}{|c|}{$\mathrm{h} / \mathrm{L}=1.00$} \\
\hline$\rho(\%)$ & 0.0 & 0.1 & 0.2 & 0.4 & 0.6 \\
\hline 0.00 & FL (R) / FL (R) & $\mathrm{FL}(\mathrm{R}) / \mathrm{SH}$ & $\mathrm{FL}(\mathrm{R}) / \mathrm{SH}$ & $\mathrm{FL}(\mathrm{C}) / \mathrm{SH}$ & FL (C) / SH \\
\hline 0.03 & $\mathrm{FL}(\mathrm{R}) / \mathrm{FL}(\mathrm{R})$ & $\mathrm{FL}(\mathrm{R}) / \mathrm{M}$ & FL (R) / SH & FL (C) / SH & $\mathrm{FL}(\mathrm{C}) / \mathrm{SH}$ \\
\hline 0.05 & FL (R) / FL (R) & $\mathrm{FL}(\mathrm{R}) / \mathrm{M}$ & $\mathrm{FL}(\mathrm{R}) / \mathrm{M}$ & FL (C) / SH & $\mathrm{FL}(\mathrm{C}) / \mathrm{M}$ \\
\hline 0.08 & FL (R) / FL (R) & $\mathrm{FL}(\mathrm{R}) / \mathrm{M}$ & $\mathrm{FL}(\mathrm{R}) / \mathrm{M}$ & FL (C) / M & FL (C) / M \\
\hline
\end{tabular}


Table 4 - Failure modes of reinforced shear walls with variation of vertical reinforcement (cantilever/ fixed end).

\begin{tabular}{|c|c|c|c|c|c|}
\hline & \multicolumn{5}{|c|}{$\sigma / f_{a}=0.2$} \\
\hline $\mathrm{h} / \mathrm{L}$ & 2.33 & 1.40 & 1.00 & 0.78 & 0.64 \\
\hline 0.00 & FL (R) / FL (R) & FL (R) / SH & FL (R) / SH & $\mathrm{SH} / \mathrm{SH}$ & $\mathrm{SH} / \mathrm{SH}$ \\
\hline 0.03 & $\mathrm{FL}(\mathrm{Y}) / \mathrm{FL}(\mathrm{Y})$ & FL (Y) / SH & FL (Y) / SH & $\mathrm{SH} / \mathrm{SH}$ & $\mathrm{SH} / \mathrm{SH}$ \\
\hline 0.05 & $\mathrm{FL}(\mathrm{Y}) / \mathrm{M}$ & $\mathrm{FL}(\mathrm{Y}) / \mathrm{SH}$ & FL (Y) / SH & $\mathrm{SH} / \mathrm{SH}$ & $\mathrm{SH} / \mathrm{SH}$ \\
\hline \multirow[t]{2}{*}{0.08} & FL (Y) / SH & FL (Y) / SH & $\mathrm{M} / \mathrm{SH}$ & $\mathrm{SH} / \mathrm{SH}$ & $\mathrm{SH} / \mathrm{SH}$ \\
\hline & \multicolumn{5}{|c|}{$\mathrm{h} / \mathrm{L}=1.00$} \\
\hline$\rho(\%)$ & 0.0 & 0.1 & 0.2 & 0.4 & 0.6 \\
\hline 0.00 & FL (R) / FL (R) & FL (R) / SH & FL (R) / SH & FL (C) / SH & $\mathrm{FL}(\mathrm{C}) / \mathrm{SH}$ \\
\hline 0.03 & FL (Y) / FL (Y) & FL (Y) / SH & FL (Y) / SH & FL (Y) / SH & FL (C) / SH \\
\hline 0.05 & $\mathrm{FL}(\mathrm{Y}) / \mathrm{M}$ & $\overline{\mathrm{FL}}(\mathrm{Y}) / \mathrm{SH}$ & FL (Y) / SH & $\mathrm{M} / \mathrm{SH}$ & $\overline{\mathrm{FL}}(\mathrm{C}) / \mathrm{SH}$ \\
\hline 0.08 & $\mathrm{M} / \mathrm{SH}$ & $\mathrm{M} / \mathrm{SH}$ & $\mathrm{M} / \mathrm{SH}$ & $\mathrm{M} / \mathrm{SH}$ & $\mathrm{FL}(\mathrm{C}) / \mathrm{SH}$ \\
\hline
\end{tabular}

